\title{
Review Article Biology of the KCNQ1 Potassium Channel
}

\author{
Geoffrey W. Abbott \\ Bioelectricity Laboratory, Department of Pharmacology and Department of Physiology and Biophysics, School of Medicine, \\ University of California, 360 Med Surge II, Irivine, CA 92697, USA \\ Correspondence should be addressed to Geoffrey W. Abbott; abbottg@uci.edu
}

Received 5 September 2013; Accepted 22 November 2013; Published 29 January 2014

Academic Editor: Lydie Combaret

Copyright (C) 2014 Geoffrey W. Abbott. This is an open access article distributed under the Creative Commons Attribution License, which permits unrestricted use, distribution, and reproduction in any medium, provided the original work is properly cited.

Ion channels are essential for basic cellular function and for processes including sensory perception and intercellular communication in multicellular organisms. Voltage-gated potassium (Kv) channels facilitate dynamic cellular repolarization during an action potential, opening in response to membrane depolarization to facilitate $\mathrm{K}^{+}$efflux. In both excitable and nonexcitable cells other, constitutively active, $\mathrm{K}^{+}$channels provide a relatively constant repolarizing force to control membrane potential, ion homeostasis, and secretory processes. Of the forty known human Kv channel pore-forming $\alpha$ subunits that coassemble in various combinations to form the fundamental tetrameric channel pore and voltage sensor module, KCNQ1 is unique. KCNQ1 stands alone in having the capacity to form either channels that are voltage-dependent and require membrane depolarization for activation, or constitutively active channels. In mammals, KCNQ1 regulates processes including gastric acid secretion, thyroid hormone biosynthesis, salt and glucose homeostasis, and cell volume and in some species is required for rhythmic beating of the heart. In this review, the author discusses the unique functional properties, regulation, cell biology, diverse physiological roles, and involvement in human disease states of this chameleonic $\mathrm{K}^{+}$channel.

\section{Introduction}

Ion channels facilitate the transmembrane movement of aqueous ions across lipid bilayers and down an electrochemical gradient at rates that can approach the diffusion limit. Incredibly, many also achieve selectivity ratios estimated at $100: 1$, even for $\mathrm{K}^{+}$over the similarly charged but smaller $\mathrm{Na}^{+}$ [1]. These multimembrane-spanning domain proteins are best known for their roles in excitable cell processes including electrical signaling in the brain and muscular contraction. Neuronal action potentials, often of simple morphology and on the scale of several milliseconds, primarily require voltagegated $\mathrm{Na}^{+}$-selective (Nav) channels to provide the pathway for $\mathrm{Na}^{+}$influx into the cell that creates the upstroke or depolarization (Figure 1(a)) [2]. Kv channels open in response to the depolarization to form a conduit for $\mathrm{K}^{+}$efflux and thus the downstroke or repolarization (Figure 1(a)) [3]. In cardiac myocytes, especially of larger mammals including humans, the action potential is hundreds of milliseconds in duration, requiring slower-activating $\mathrm{K}^{+}$channels [4] and also significant contribution from $\mathrm{Ca}^{2+}$ influx (through voltage-gated $\mathrm{Ca}^{2+}$ channels and $\mathrm{Ca}^{2+}$-activated $\mathrm{Ca}^{2+}$-release channels) in addition to $\mathrm{Na}^{+}$influx to potentiate the depolarizing force and create a plateau phase (Figure 1(b)).

1.1. Voltage-Dependent Ion Channel Gating. The crucial elements in generating an action potential in terms of an ion channel are voltage sensitivity and ion selectivity; in turn, the ion channel requires specific ionic gradients and an otherwise relatively impermeable cell membrane such that gating of the channel can "control" the passage of ions [57]. Voltage-gated ion channels share a defining feature-a voltage sensor module or paddle that contains at its heart a transmembrane helix (segment 4 or S4) with periodic basic residues [8]. These basic residues "sense" membrane potential by moving across the membrane electric field in response to membrane potential changes (Figures $1(\mathrm{c})-1(\mathrm{e})$ ). These movements are communicated to the channel pore by an intracellular linker region (S4-5 in Kv channels) and/or direct interactions between the pore-lining helix, ion selectivity filter, and S4 [9]. Other elements of the voltage sensor module (S1 and S2) contain acidic residues that are thought to shield or stabilize $\mathrm{S} 4$ as it migrates to the open state position upon membrane depolarization $[10,11]$. Thus, voltage-gated ion 


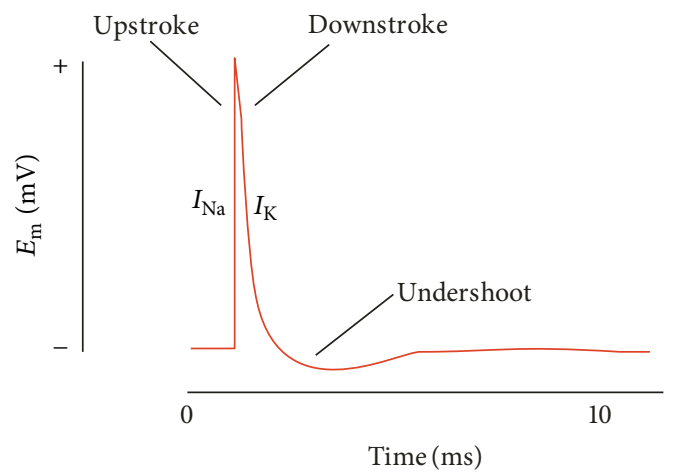

(a)
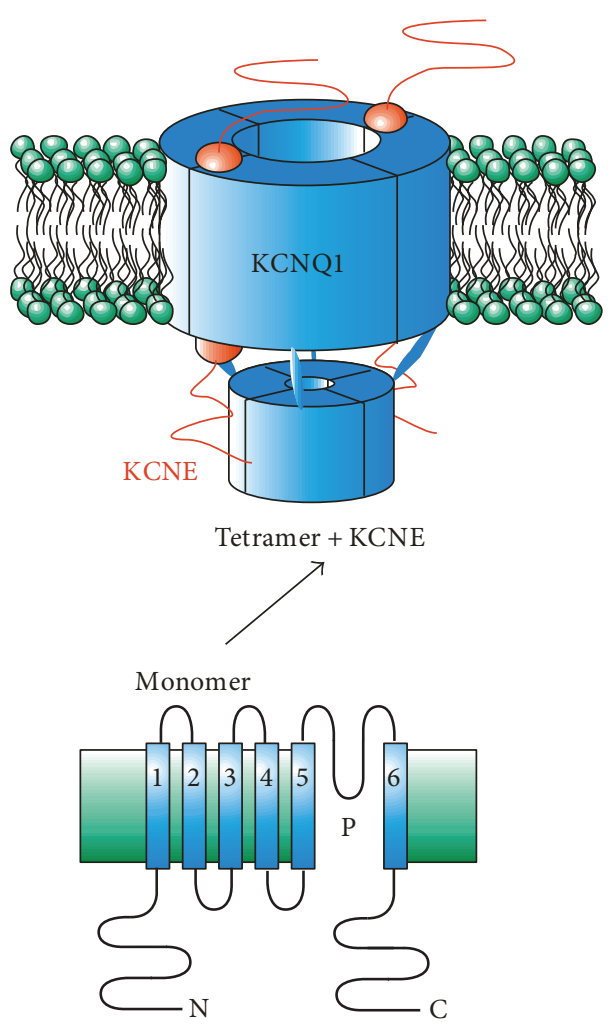

(c)

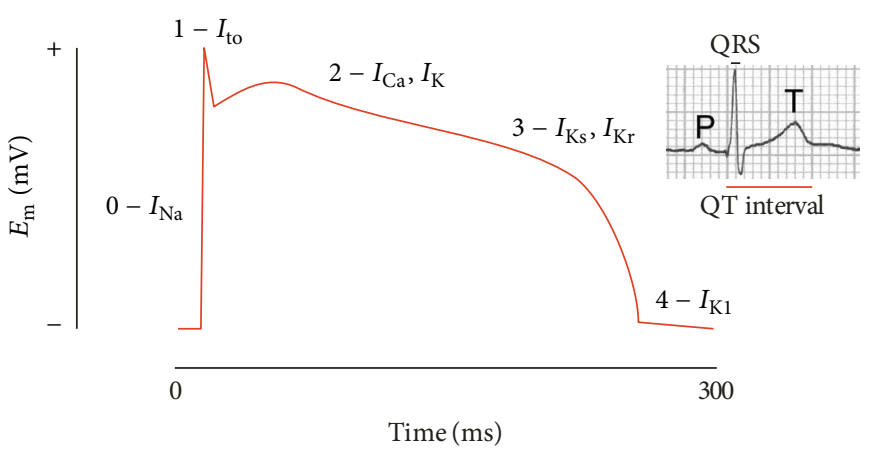

(b)

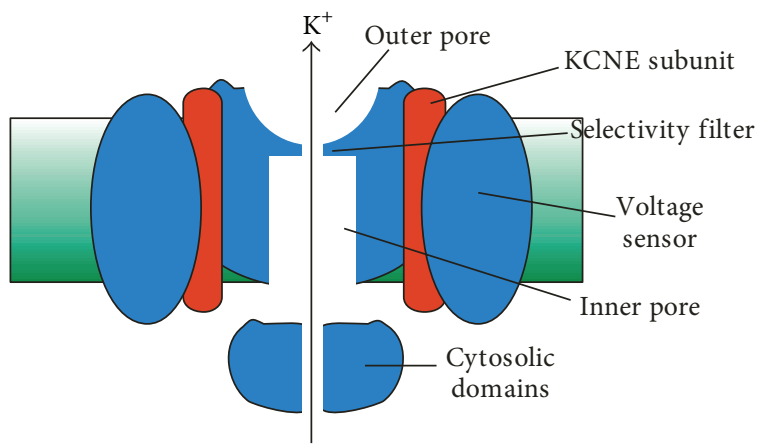

(d)

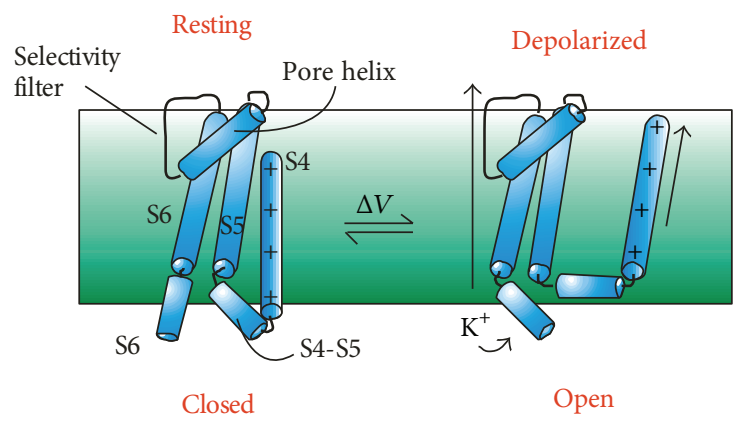

(e)

FIgURE 1: Kv channels and the action potential. (a) Neuronal action potentials often last less than $10 \mathrm{~ms}$, with an upstroke caused by Na ${ }^{+}$ influx and downstroke and undershoot caused by $\mathrm{K}^{+}$efflux. $E_{\mathrm{m}}$ is the membrane potential. (b) Human ventricular myocyte action potentials last several hundred ms. The upstroke $(0)$ is caused by $\mathrm{Na}^{+}$influx, initial repolarization notch is caused by the transient outward $\mathrm{K}^{+}$current $\left(I_{\text {to }}\right)$, and the plateau phase (2) is a balance between residual $\mathrm{Na}^{+}$current, $\mathrm{Ca}^{2+}$ influx, and $\mathrm{K}^{+}$efflux $\left(I_{\mathrm{K}}\right)$. Repolarization (3) is primarily achieved by $I_{\mathrm{Ks}}$ (mediated by KCNQ1-KCNE1 and possibly other KCNQ1-KCNE combinations) and $I_{\mathrm{Kr}}$. Inward rectifiers $\left(I_{\mathrm{K} 1}\right)$ help determine resting $E_{\mathrm{m}}$ between action potentials. Upper right inset: surface electrocardiogram showing P wave, QRS complex, T wave, and QT interval. (c) Upper, cartoon of KCNQ1-KCNE complex; lower, topology diagram of KCNQ1 monomer. (d) Section through KCNQ1-KCNE complex showing main features. (e) Cartoon of voltage gating depicting the S4-S6 portions of a Kv $\alpha$ subunit monomer and the type of conformational changes that may occur upon membrane depolarization.

channel gating is electromechanically coupled to membrane potential (Figure 1(e)) [12].

Voltage-gated ion channels share another common feature, pseudo-fourfold symmetry. In Nav and Cav channels this is achieved by one contiguous pore-forming $(\alpha)$ subunit with four repeating units being encoded by a single gene and is approximate because the sequences of each repeating unit are slightly different from one another (most notably in the loops between membrane-spanning segments) $[13,14]$. In $\mathrm{Kv}$ channels each repeating unit is a separate gene product 
and a tetramer of $\alpha$ subunits forms cotranslationally. Each unit contains 6 transmembrane segments, with segments 14 (S1-S4) forming one voltage sensor module, and S5 and S6 contributing from each unit forming one quarter of an interlocking pore structure (Figures 1(c) and 1(d)) [15-19].

All voltage-gated ion channel $\alpha$ subunits are regulated by an array of non-pore-forming ancillary $(\beta)$ subunits (addressed in detail with respect to KCNQ1 below) [20-22]. Once the pore of the voltage-gated ion channel is opened, ion selectivity is crucial. In $\mathrm{K}^{+}$channels, selectivity over similar ions including $\mathrm{Na}^{+}$is achieved by backbone carbonyl oxygen atoms of glycine residues within the canonical GYGD $\mathrm{K}^{+}$selectivity filter motif forming an aquamimetic "hydration" shell that fits $\mathrm{K}^{+}$but is slightly too big to efficiently coordinate $\mathrm{Na}^{+}$. Thus, rapid movement of ions through the $\mathrm{K}^{+}$channel pore (of both $\mathrm{Kv}$ and voltage-independent $\mathrm{K}^{+}$ channels) requires binding and unbinding of ions to the pore elements, which have evolved to fit $\mathrm{K}^{+}$better than all other physiologically abundant ions $[18,23,24]$.

In early studies of squid giant axon action potentials, decades before the cloning of voltage-gated ion channels, it was recognized by Hodgkin and Huxley that the squid giant axon Nav channel both activates and inactivates rapidly (millisecond timescale) $[5,6,25]$. Inactivation of voltagegated ion channels occurs while the activation gate is still open and the membrane is still depolarized and is a process distinct from closing (deactivation) of the activation gate which essentially occurs after membrane repolarization. In squid giant axons, the primary Kv current did not inactivate appreciably in the timescale of the seminal experiments, but nuances of this and other excitable systems have since been fleshed out further. It is now established that almost all Kv channels undergo a slow inactivation process (most often termed C-type inactivation) which typically occurs over seconds or tens of seconds [26-33]. A subset of Kv channels also undergoes rapid inactivation, typically termed $\mathrm{N}$-type inactivation because it involves plugging of the pore by an $\mathrm{N}$ terminal inactivation domain or "ball" domain $[34,35]$.

1.2. Gating in Non-S4 Ion Channels. In contrast to the voltagesensitive, S4-containing ion channels, a range of other ion channels, gated by other factors including mechanical stimuli, temperature, metal ions, other ligands, or other ion channels, form the vast ionic signaling network that controls or regulates virtually every biological process. Focusing on $\mathrm{K}^{+}$-selective channels, aside from the Kv channels, the major known classes are the inward rectifiers ( $\mathrm{K}_{\mathrm{ir}}$ channels) and the two-pore $\mathrm{K}^{+}$leak channels ( $\mathrm{K}_{2 \mathrm{P}}$ channels). $\mathrm{K}_{\mathrm{ir}}$ channels are, like Kv channels, formed of tetramers [36], but they lack S1S4; are constitutively open at negative voltages but subject to various regulatory processes [37]; and are inwardly rectifying because of increasingly strong pore block by intracellular $\mathrm{Mg}^{2+}[38,39]$ or polyamines [40] at increasingly depolarized membrane potentials.

$\mathrm{K}_{2 \mathrm{P}}$ channels are dimers [41, 42], each subunit containing two of the repeating units that come together to form a pseudo-fourfold symmetrical pore (hence two-pore or $\mathrm{K}_{2 \mathrm{P}}$ ) $[43,44]$; they are gated by a wide range of factors and together with some $\mathrm{K}_{\mathrm{ir}}$ channels contribute a "background"
$\mathrm{K}^{+}$conductance that drives the membrane potential toward the $\mathrm{K}^{+}$equilibrium potential, $E_{\mathrm{K}}$ [45]. $E_{\mathrm{K}}$ is typically close to $-80 \mathrm{mV}$ in physiological ionic conditions and thus these background channels contribute to setting the resting membrane potential at a negative voltage (together with the $\mathrm{Na}^{+} / \mathrm{K}^{+}$pump and the Donnan effect). $\mathrm{K}_{\text {ir }}$ (and potentially $\mathrm{K}_{2 \mathrm{P}}$ ) channels also contribute to correcting the hyperpolarization that occurs, for example, between cardiac myocyte action potentials by allowing $\mathrm{K}^{+}$influx at voltages negative to $E_{\mathrm{K}} \cdot \mathrm{K}_{\mathrm{ir}}$ variants such as the $\mathrm{K}_{\mathrm{ATP}}$ channels couple membrane potential to cellular metabolic state [46].

1.3. KCNQ1 Is Unique: It Contains S4 but Can Lose Its Voltage Dependence. The KCNQ1 Kv $\alpha$ subunit is among the most highly studied ion channels because of its association with human disease, its plethora of roles in physiology, and its fascinating functional eccentricities. As the founding member of the KCNQ subfamily of five related genes, within the 40-member Kv $\alpha$ subunit gene family (Figure 2), KCNQ1 is unique among the KCNQ gene products (Figure 3) and indeed all known voltage-gated ion channel pore-forming $(\alpha)$ subunits represented in the human genome. This is because it can "switch teams" from the voltage-dependent to the constitutively active side. Although KCNQ1 possesses a voltage sensor, it can be modified to substantially lose its voltage dependence such that at physiological voltages (and even substantially more hyperpolarized voltages) it is constitutively active. This duality is achieved by coassembly with members of the KCNE family of ancillary $(\beta)$ subunits [4750]. KCNE subunits interact with a large number of different $\mathrm{Kv} \alpha$ subunits quite promiscuously, but KCNQ1 is unique in that of the known KCNE-interacting $\alpha$ subunits, it exhibits the widest known range of functional outcomes (covered in detail below) [20]. These and other unique properties permit KCNQ1 to serve an astonishingly numerous and diverse array of functional roles in both excitable and nonexcitable cell types and have ensured it is one of the most widely studied ion channels, with scientists from multiple disciplines dissecting aspects of KCNQ1 genetics, physiology, structure-function, regulation, and pathology.

\section{A Molecular Toolkit of KCNE Subunits Facilitates the Diverse Roles of KCNQ1}

KCNQ1 interacts with all five members of the KCNE family of single transmembrane domain ancillary or beta subunits (also called MinK-related peptides, MiRPs) [20]. While homomeric KCNQ1 channels function when heterologously expressed [47, 48], it is highly likely that KCNQ1 is always associated with one or more KCNE subunits in vivo [51]. To date, no native current has been described that displays the attributes of homomeric KCNQ1 channels, while several native currents exhibit functional features characteristic of specific KCNQ1-KCNE heteromers. Current knowledge of the functional attributes and physiological roles of the five bipartite complexes formed by KCNQ1 and KCNE subunits is described below. 


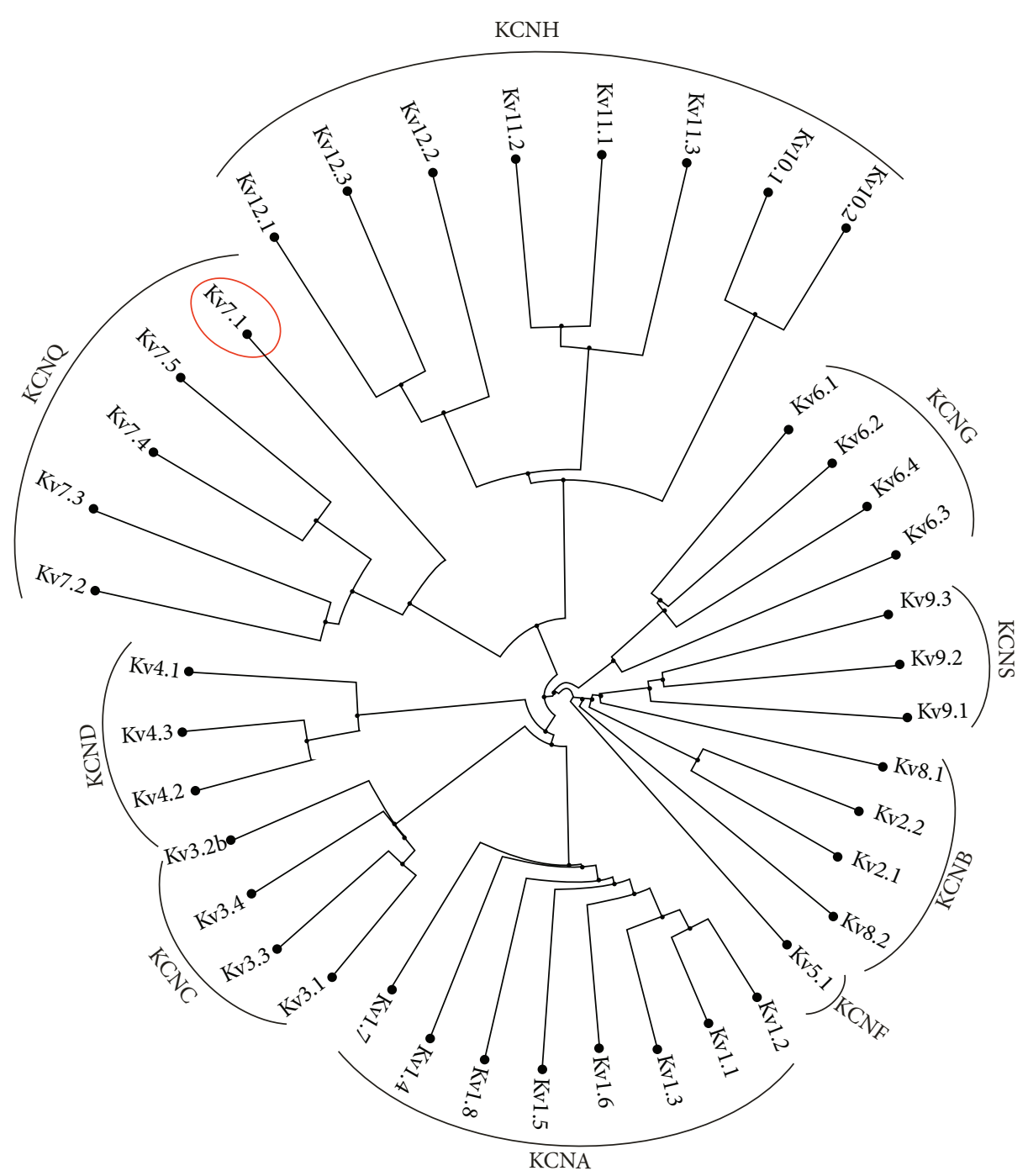

FIGURE 2: KCNQ1 within the human Kv channel $\alpha$ subunit gene family. Clustal alignment phylogram with nodes, showing KCNQ1 (Kv7.1, circled red) in relation to the other 39 human $\mathrm{Kv}$ channel $\alpha$ subunits. Subfamilies indicated with bold brackets.

303

Kv7.1 RLLGSVVFIHRQELITTLYIGFLGLIFSSYFVYLAEKDAVN-----ESGRVEFGSYADAL

KV7.3 KLLGSAICAHSKELITAWYIGFLTLILSSFLVYLVEKDVPEVDAQGEEMKEEFETYADAL

Kv7.2 KLLGSVVYAHSKELVTAWYIGFLCLILASFLVYLAEKGE----------NDHFDTYADAL

Kv7.4 KLLGSVVYAHSKELITAWYIGFLVLIFASFLVYLAEKDA----------NSDFSSYADSL

Kv7.5 KLLGSVVYAHSKELITAWYIGFLVLIFSSFLVYLVEKDA----------NKEFSTYADAL

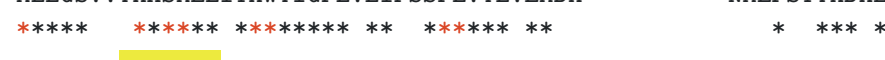

$\mathrm{SF}$

363

KV7.1 WWGVVTVTTIGYGDKVPQTWVGKTIASCFSVFAISFFALPAGILGSGFALKVQQKQRQKH

Kv7.3 WWGLITLATIGYGDKTPKTWEGRLIAATFSLIGVSFFALPAGILGSGLALKVQEQHRQKH

KV7.2 WWGLITLTTIGYGDKYPQTWNGRLLAATFTLIGVSFFALPAGILGSGFALKVQEQHRQKH

Kv7.4 WWGTITLTTIGYGDKTPHTWLGRVLAAGFALLGISFFALPAGILGSGFALKVQEQHRQKH

Kv7.5 WWGTITLTTIGYGDKTPLTWLGRLLSAGFALLGISFFALPAGILGSGFALKVQEQHRQKH

$* * * * * * * * * * * * * * * * * * * \quad * * * * * * * * * * * * * * * * * * * * * * * * * * * * * *$

Figure 3: KCNQ1 within the human KCNQ $\alpha$ subunit gene family. Clustal alignment of all five KCNQ (Kv7) subfamily members showing the selectivity filter (SF, shaded yellow) and surrounding residues, to illustrate sequence differences (red letters) between KCNQ1 (Kv.1) and other family members. Black asterisks, conserved residues; red asterisks, residues conserved in all KCNQ family members except KCNQ1; Numbers, human KCNQ1 protein sequence numbering. Order of sequences was automatically determined by sequence similarity within Clustal. 


\subsection{KCNQ1-KCNE1: A New Type of Channel Complex Is Discovered and Linked to $I_{K s}$}

2.1.1. KCNQ1-KCNE1 in Cardiac Function and Disease. The story of KCNQ1 begins, paradoxically, with the cloning of a small ancillary subunit that on its own can generate no current. Injection by Takumi and colleagues of fractionated rat kidney mRNA into oocytes of the African clawed toad, Xenopus laevis, produced an unusually slow-activating, voltage-dependent $\mathrm{K}^{+}$current and led to the cloning of a single transmembrane domain protein termed MinK (for minimal $\mathrm{K}^{+}$channel), thought to form a $\mathrm{K}^{+}$-selective channel $[52,53]$. MinK is now more commonly referred to by its gene name, KCNE1. Likewise, the MinK-related peptides (MiRPs) are now typically referred to by their gene names (KCNE2-5) and this nomenclature will be utilized herein to avoid confusion. In keeping with general nomenclature standards, use of italics indicates reference to the gene rather than the protein, and lower case indicates reference to the mouse gene/protein whereas upper case implies human gene/protein.

The current formed by KCNE1 cRNA injection was recognized to resemble the cardiac slow-activating $\mathrm{K}^{+}$current, $I_{\mathrm{Ks}}$, important in human and guinea pig ventricular repolarization [54], but the single-transmembrane-domain architecture was unlike that of other known $\mathrm{K}^{+}$channels. Some eight years following the cloning of KCNE1, human KCNQ1 (originally termed KvLQT1) was positionally cloned and found to be associated with the LQT1 form of the cardiac arrhythmia, Long QT Syndrome (LQTS) [55]. It was also discovered that KCNE1 does not form channels alone [56, 57] but increases endogenous Xenopus oocyte KCNQ1 channel current $[47,48]$. KCNQ1-KCNE1 channels were found to be the molecular correlate of human and guinea pig cardiac $I_{\mathrm{Ks}}$, and mutations in the human KCNE1 gene were found to underlie the LQT5 form of inherited LQTS $[58,59]$. LQT5 gene mutations typically cause loss-of-function of KCNQ1KCNE1 channels and in some cases also impair hERG and Kv2.1 function, as KCNE1 also associates with these channel $\alpha$ subunits [60-62].

KCNQ1 was originally named KvLQT1 reflecting the manner in which it was discovered-by positional cloning to identify the causative gene in specific cases of LQTS [55]. LQTS is an inherited (or in many cases drug-induced) cardiac rhythm disorder in which the QT interval on the surface electrocardiogram-reflecting the time from initiation of ventricular depolarization to the end of ventricular repolarization-is prolonged. This delay in repolarization, caused by loss-of-function gene variants in $\mathrm{K}^{+}$channel genes such as KCNQ1, can cause the potentially lethal cardiac arrhythmia, torsades de pointe, and ultimately ventricular fibrillation, which can cause sudden cardiac death unless reversed by defibrillation within a few minutes $[63,64]$.

In human ventricular myocytes, KCNQ1-KCNE1 channels generate $I_{\mathrm{Ks}}$, a slowly activating $\mathrm{K}^{+}$current that is important for timely myocyte repolarization particularly when other repolarizing currents are compromised or during exercise or other conditions of increased sympathetic tone. In particular, KCNE1 endows the complex with kinetic properties that permit the channel to accumulate a cache of channel closed states near the channel open state, facilitating rapid channel opening when required [65]. The other major human ventricular myocyte repolarization current, $I_{\mathrm{Kr}}$, is generated by the human ether-à-go-go related gene product (hERG or KCNH2) Kv channel $\alpha$ subunit [66]. Like KCNQ1, hERG is also regulated by KCNE1 and KCNE2 [62, 67], with ongoing debate over the relative importance of either mode of regulation in different species and in different human heart regions [68]. Additionally, adding to the complexity of interpreting LQTS disease mechanisms, KCNQ1 forms complexes with hERG in vitro [69] and appears to do so in vivo $[70,71]$.

Among the positively sequenced examples of inherited LQTS, mutations identified in the genes encoding KCNQ1 and hERG each amount to $35-45 \%$ of cases, making inherited or sporadic sequence variants in these two genes the primary underlying cause of inherited Long QT Syndrome-reflecting their essential role in ventricular repolarization [72]. While gain-of-function mutations in cardiac Nav channel gene SCN5A (encoding Nav1.5) are the next most common cause, albeit rarer association of mutations in all of the KCNE genes with Long QT Syndrome and/or other cardiac arrhythmias also strongly support a direct cardiac role [73].

Briefly, KCNE1 and KCNE2 gene variants each account for up to $1 \%$ of sequenced Long QT Syndrome cases. In the case of KCNE1 this probably mostly reflects KCNQ1-KCNE1 $\left(I_{\mathrm{Ks}}\right)$ dysfunction; in the case of KCNE2, it suggests dysfunction mostly of channels formed with hERG $\left(I_{\mathrm{Kr}}\right)$ and/or Kv4.x $\left(I_{\text {to }}\right)$. Association of gene sequence variants within KCNE15 with atrial fibrillation most likely reflects perturbation of channels formed with KCNQ1, while the association of KCNE3 gene variants with ventricular arrhythmias is suggested to arise from malfunctioning Kv4.x-KCNE3 channels (e.g., in Brugada Syndrome) [73].

KCNQ1 gain-of-function mutations have also been associated with the rarer but equally dangerous Short QT Syndrome, in which early ventricular myocyte repolarization triggers fatal arrhythmias [74], and also with familial atrial fibrillation [75]. A relatively rare form of atrial fibrillation (most cases being linked to structural abnormalities), familial or idiopathic atrial fibrillation is nonetheless of interest both mechanistically and from a public health standpoint because there are so many cases of this aging-related disease (an estimated 2-3 million in the United States). As with the ventricular-manifested Short QT Syndrome, atrial fibrillation, is linked to shortening of the action potential, which in the atria is already relatively short compared to that in human ventricular myocytes. It is not known with which KCNE subunits KCNQ1 associates in human atria, but atrial fibrillation-associated KCNQ1 gene variants have been shown to increase whole-cell currents through homomeric KCNQ1 and heteromeric KCNQ1-KCNE channels [75]. KCNE gene variants that modulate currents through heteromeric channels formed with KCNQ1 have also been implicated both in idiopathic forms of atrial fibrillation and in protection against it [76-82].

The mouse has not been an especially useful model to study Kcnq1 function directly in the heart because adult 
mouse ventricular myocytes do not express Kcnq1 to any great extent (if at all); although, in neonates, which do exhibit cardiac Kcnq1 protein and $I_{\mathrm{Ks}}$ current expression, Kcnq1 deletion impaired $I_{\mathrm{Ks}}$ in a manner exacerbated by isoproterenol [83]. In contrast, adult $\mathrm{Kcnq1}^{-/-}$mice have been an excellent model for investigating the mechanisms of disorders involving KCNQ1 dysfunction in polarized epithelial cells. These include one half of the disorder Jervell and LangeNielsen Syndrome (JLNS), which in humans is typically an autosomal recessive disorder caused by KCNQ1 or KCNE1 loss-of-function mutations being present in both alleles. JLNS manifests as severe Long QT Syndrome combined with profound sensorineural deafness, the latter aspect of which has been studied intensively using the Kcnq1 ${ }^{-/-}$mouse $[84,85]$. Note that the more common autosomal dominant form of KCNQ1-linked Long QT Syndrome is referred to as Romano-Ward Syndrome and is not usually accompanied by hearing loss $[55,86]$.

2.1.2. Mechanisms of KCNQ1 Functional Modulation by KCNE1. KCNE1 modulates KCNQ1 function in multiple crucial aspects (Figure 4). The most noticeable feature is that KCNQ1 activation is slowed 5- to 10 -fold by KCNE1 coexpression $[87,88]$. This slow activation is important for phase 3 ventricular repolarization in human heart [48], although there are other nuances of $I_{\mathrm{Ks}}$ that render it most important during specific conditions, that is, increased heart rate (at other times, $I_{\mathrm{Kr}}$ - generated primarily by hERG - is probably the dominant repolarizing force) $[65,66,89]$. Thus, KCNQ1KCNE1 channels (but not homomeric KCNQ1 channels) are thought to accumulate a cache of near-open closed states that are available "on-demand" when required, especially during changes in heart rate. Additionally, during $I_{\mathrm{Kr}}$ diminishment by disease or drugs, this $I_{\mathrm{Ks}}$ reserve may confer protection early after-depolarizations that would otherwise occur and predispose to ventricular tachyarrhythmias $[65,90,91]$.

As with other functional properties of KCNQ1-KCNE1 channels, the mechanistic basis for the slowing of KCNQ1 activation by KCNE1 has been controversial. Two studies utilizing cysteine scanning mutagenesis of the S4 voltage sensor and nearby residues creating sensitivity to applied methanethiosulfonate (MTS) derivatives led to opposing hypotheses, with one group surmising KCNE1 retards S4 movement and therefore MTS accessibility [92]; the other finding KCNE1 directly slows pore opening [93]. Later, the Kass group suggested, based on voltage clamp fluorimetry measurements of channels expressed in Xenopus oocytes, that KCNE1 imposes a necessity for movement of multiple voltage sensors before KCNQ1 channel opening, in contrast to their findings that homomeric KCNQ1 appears to pass current even with only a single voltage sensor (of the four per channel tetramer) being activated [94, 95]. This model indicated KCNE1 might have dual effects; that is, it suggested KCNQ1-KCNE1 was slow-activating because of both slow voltage sensor movement and the requirement for multiple voltage sensors to move, for channel activation [94].

However, the Goldstein group recently cast doubts on this dual model; their findings using simultaneous cut-open oocyte recording and site-directed fluorimetry led to the conclusion that KCNE1 slows depolarization-initiated voltage sensor movement so profoundly that gating currents are immeasurable, whereas those through homomeric KCNQ1 are resolvable (and themselves found to be 28-fold slower than those of the canonical Drosophila Kv channel, Shaker) [90]. Thus, in this model KCNE1 slows KCNQ1 activation solely by slowing S4 "activation." Finally, in a recent study from the Fedida lab employing single channel measurements, rapid flickering between multiple subconductance states with fast closings was observed in KCNQ1-KCNE1 unitary currents, and it was concluded that this exotic behavior (not previously observed in any other "wild-type" human potassium channel) strongly influences $I_{\mathrm{Ks}}$ activation and deactivation kinetics [91]. This idea is not necessarily mutually exclusive with data from the Goldstein lab using macroscopic evidence to show slow voltage sensor movement, but the question persists of whether voltage sensor movement itself could dictate flicker or whether the flicker is solely indicative of pore/selectivity filter status.

KCNE1 increases macroscopic KCNQ1 currents by varying degrees depending upon the expression system and voltage variability that can be traced to the multiplicity of KCNE1 effects and to their differing regulation in different systems $[20,96]$. Aside from slowing KCNQ1 activation, KCNE1 right-shifts the voltage dependence of KCNQ1 activationwhich would tend to decrease current at a given voltage, but KCNE1 also increases KCNQ1 unitary conductance, counteracting this [87]. KCNE1 is thought to interact with S4, the membrane potential-sensing positively charged helix within the voltage sensor module of KCNQ1. In doing this it probably also perturbs the way in which $\mathrm{S} 4$ charges are stabilized by surrounding acidic residues in KCNQ1, thus shifting how S4 responds to voltage and causing the rightshift in the voltage dependence of activation [97-99].

Previous reports of noise variance analysis of KCNQ1 current indicated unitary current is increased by KCNE1 (three- to fivefold) although the absolute values of unitary conductance varied between each of these studies and with the recent study utilizing direct measurement by single channel recording. This disagreement probably arises from the "flickery" nature of KCNQ1-KCNE1 currents, as the channels jump between various open and closed states without truly deactivating. Indeed, direct single-channel recordings recently revealed five unitary conductance states, and the suggestion was forwarded that gating kinetics of Kv channels in general may be tied to shifts between multiple conductance states, but that in typical Kv channels these transitions have not been resolved because their gating is much quicker than that of KCNQ1-KCNE1 [87, 91, 100].

One of the more profound effects of KCNE1 is to eliminate KCNQ1 slow inactivation [101]. Slow inactivation occurs over several seconds to tens of seconds and is most often referred to as C-type inactivation because it was initially linked experimentally to the C-terminal end of the porelining S6 helix in Shaker channels and was evident after removal of the N-terminal inactivation domain [34]. Slow inactivation variants that may differ mechanistically from Ctype are referred to as P-type (pore-type) or U-type (because 


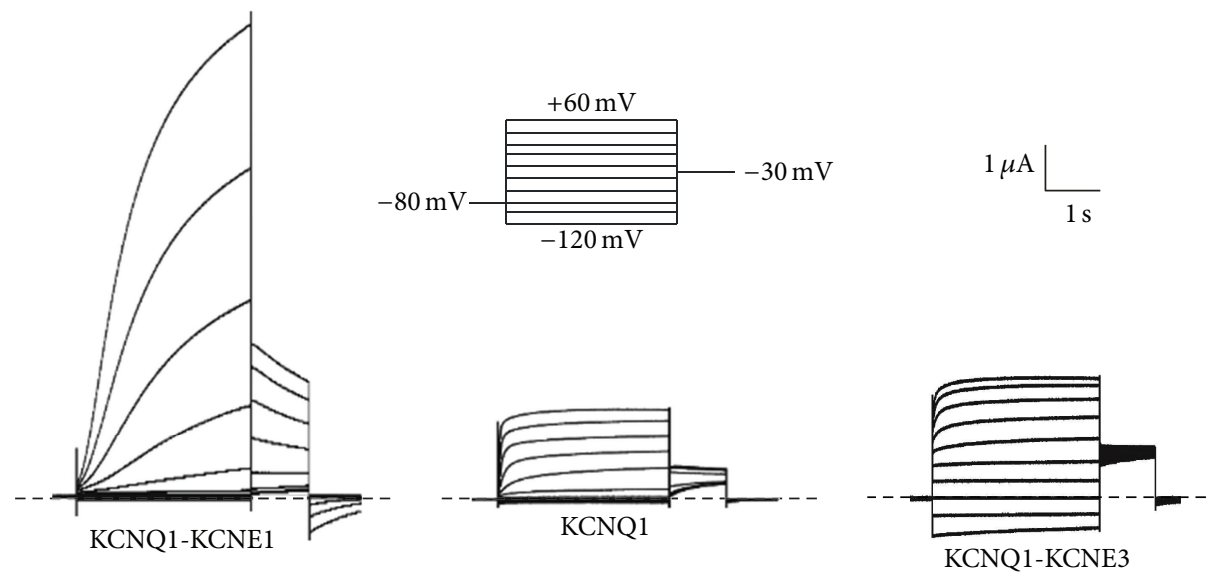

FIGURE 4: Functional effects of KCNE1 and KCNE3 on KCNQ1. KCNQ1, KCNQ1-KCNE1, and KCNQ1-KCNE3 currents in response to $3 \mathrm{~s}$ pulses to a range of voltages between $-120 \mathrm{mV}$ and $+60 \mathrm{mV}$, with $10 \mathrm{~s}$ interpulse intervals, from a holding voltage of $-80 \mathrm{mV}$, with a $1 \mathrm{~s}-30 \mathrm{mV}$ tail pulse, as shown in voltage protocol (upper center). Channels were expressed by injection of corresponding cRNAs into Xenopus laevis oocytes and currents recorded 3 days after injection by two-electrode voltage-clamp. Zero current levels indicated by dashed lines.

of a U-shaped voltage dependence), although there is likely some overlap between the channel regions involved in each of these processes $[31,33]$. One common theme is thought to be a structural rearrangement in the pore and/or selectivity filter region following activation, which leads to loss of $\mathrm{K}^{+}$ conduction through either pore collapse or apparent collapse paradoxically because of dilation of the pore, removing the ability to effectively coordinate $\mathrm{K}^{+}$ions [102].

Slow inactivation is readily evident in experimental conditions that permit depolarization pulses in the range of tens of seconds if desired, with inactivation appearing as current decay during the depolarizing step. In normal excitable cell function, this type of long uninterrupted depolarization usually does not occur; nevertheless, slow inactivation can accumulate over successive action potentials if the recovery interval between each depolarization is insufficiently long and/or insufficiently hyperpolarizing (depolarizationactivated ion channels recover from inactivation more rapidly the more negative the voltage). Thus, even slow inactivation is physiologically essential and contributes to a cell's memory of preceding action potentials [103]. In the case of KCNQ1 in the heart, removal of inactivation by KCNE1 could ensure that there is sufficient repolarizing current to sustain repeated ventricular action potentials even at rapid heart rates, a property essential for uninterrupted cardiac function.

2.1.3. KCNQ1-KCNE1 in the Inner Ear. In the inner ear, KCNQ1-KCNE1 is thought to facilitate $\mathrm{K}^{+}$recycling in the endolymph [104, 105]. Hence, autosomal mutations in (or in the mouse, targeted deletion of) either KCNQ1 [84, 86, $106]$ or KCNE1 [58, 59, 107] can cause deafness if the loss of function is sufficiently severe. In humans this typically occurs when the individual harbors loss-of-function KCNQ1 or KCNE1 sequence variants in both alleles, causing the autosomal recessive cardioauditory JLNS. In this case, the capacity of KCNQ1-KCNE1 to sustain current for long periods without inactivating may be important for function. Although activation of KCNQ1-KCNE1 channels is strongly voltage-dependent (unlike KCNQ1 with KCNE2 or KCNE3), they open at membrane potentials positive to $-40 \mathrm{mV}$ and because they do not inactivate they remain open at these voltages. As the membrane potential across the apical membrane of inner ear dark cells and strial marginal cells is between 0 and $+10 \mathrm{mV}$ [108], KCNQ1-KCNE1 is therefore constitutively active and constitutes the predominant (and perhaps the only) $\mathrm{K}^{+}$secretion pathway in this location [109]. The effects of KCNE1 on currents passed by KCNQ1, contrasted with effects of KCNE3 on KCNQ1, are shown in Figure 4.

2.1.4. KCNQ1-KCNE1 in the Pancreas. KCNQ1 and KCNE1 are both expressed in mammalian pancreas [110, 111]. Results from overexpression studies in the MIN6 mouse $\beta$ cell line suggested that KCNQ1 may act to limit insulin secretion from pancreatic $\beta$ cells [112], although it is possible that KCNQ1 overexpression does not bear on normal physiologic mechanisms of pancreatic function. The WTC-dfk rat, which bears an intragenic deletion in the KCNQ1 gene, exhibits pancreatic metaplasia [113], although this does not necessarily imply direct disruption of a primary role in the pancreas. More convincingly, KCNQ1 antagonists HMR1556 and chromanol 293B were discovered to inhibit whole-cell outward $\mathrm{K}^{+}$ currents, alter action potential duration and frequency, and increase insulin secretion from the rat $\beta$-cell derived INS-1 cell line [114].

In addition, single nucleotide polymorphisms (SNPs) within KCNQ1 are strongly linked to type 2 diabetes mellitus [115-119], gestational diabetes [120], insulin secretion [121], impaired fasting glucose [122], and susceptibility to diabetic nephropathy [123] in multiple human populations and also to efficacy of diabetic medications [124], highly suggestive of a link between altered KCNQ1 function, and human pancreatic dysfunction. Further, human pancreatic $\beta$ cells carrying human type 2 diabetes susceptibility-linked KCNQ1 gene variants were found to exhibit reduced depolarizationevoked insulin exocytosis and altered granule docking, strengthening the causal link [125]. Interestingly, Kcnq1-/- 
mice exhibit lower fed and fasted plasma glucose and insulin levels, and in mice, Kcnq1 appears to act against insulinstimulated cellular $\mathrm{K}^{+}$uptake. In this way, Kcnq1 deletion influences the downstream effects of insulin on glucose metabolism but in a manner that does not necessarily involve direct disruption of a primary role in the pancreas. Instead, these data suggest that in mice, Kcnq1 tunes the cellular glucose uptake of tissues including the liver, skeletal muscle, lungs, and kidneys [126]. In mice and humans, KCNQ1 is expressed in so many different tissues that the effects of its disruption on glucose control and handling are expected to be multifactorial in both mechanism and outcome, probably involving both the pancreas and other organs. It is also possible that the influence on diabetes of KCNQ1 locus SNPs involves a nearby gene, the imprinted expression of which is influenced by KCNQ1 or KCNQ1OT1 (see Section 3.1)the cyclin-dependent kinase inhibitor (CDKN1C) being a candidate [127].

2.1.5. KCNQ1-KCNE1 in the Kidneys. There is little doubt that both KCNQ1 and KCNE1 are expressed in mammalian kidney, but the current(s) they generate are still a matter of discussion. Kcnql and Kcnel are both expressed in the mouse kidney proximal tubule luminal membrane. Studies of $\mathrm{Kcnel}^{-/-}$mice indicated reduced late proximal and early distal tubular fluid $\mathrm{K}^{+}$concentration, suggestive of a role for Kcnel in mediating $\mathrm{K}^{+}$flux to the lumen in this region. Electrophysiological studies of isolated perfused proximal tubules supported this hypothesis and suggested a role for this $\mathrm{K}^{+}$current in maintaining constant membrane polarization in the face of electrogenic sodium-coupled transport mechanisms. Accordingly, Kcne1 ${ }^{-/-}$mice exhibit abnormally high urinary excretion of fluid, $\mathrm{Na}^{+}, \mathrm{Cl}^{-}$, and glucose [128].

Interestingly, female $\mathrm{Kcnel}^{-/-}$mice also display reduced $\mathrm{NaCl}$ consumption when offered $150 \mathrm{mM} \mathrm{NaCl}$ solution [129]; this could also indicate a perturbation in renal salt handling leading to an adverse reaction to high salt, although it could also reflect disruption of a role for Kcnel in the salivary glands. Further studies of the $\mathrm{Kcnel}^{-/-}$mouse supported a requirement for Kcnel in swelling-activated $\mathrm{K}^{+}$and $\mathrm{Cl}^{-}$currents in primary cultured proximal convoluted tubule epithelial cells, indicting a role in cell volume regulation in this tissue. The current, however, was time-independent and insensitive to $10 \mu \mathrm{M}$ chromanol 293B [130], suggesting against it being generated by a KCNQ1-KCNE1 complex (which is time-dependent and chromanol 293B-sensitive). A further study also suggested the requirement of Kcnel in mouse proximal tubule cell volume regulation [131].

Like the other four KCNE subunits, KCNE1 is promiscuous and can interact with other $\mathrm{Kv} \alpha$ subunits, possibly suggesting KCNE1 regulates a different channel in the kidney. However, KCNQ1 is expressed in proximal convoluted tubules. Another possibility is that KCNQ1 forms complexes with either KCNE2 or KCNE3 in this tissue and that KCNE1 regulates the expression or trafficking of this complex or forms with the subunits a tripartite complex with unique functional attributes. Adding to the debate, in a later study, chromanol 293B application in vivo was found to mimic
Kcne1 knockout, but the electrophysiological properties of the inhibited current were again not considered to be similar to that generated by KCNQ1, despite the chromanol sensitivity (and the $100 \mu \mathrm{M}$ chromanol 293B used may be at a sufficiently high concentration to inhibit other channel types) [132]. Importantly, Kcnq1-/- mice, when supplied with standard food and water, show normal $\mathrm{Na}^{+}$and glucose urinary excretion, in contrast to Kcne1 knockouts [133]. It seems that Kcnq1 is only crucial in mouse kidney in the context of increased substrate load, when apically expressed Kcnq1 maintains a suitable driving force to facilitate $\mathrm{Na}^{+}$reabsorption in the proximal tubule. In summary, in the mouse, Kcnel and Kcnq1 are probably each performing a physiological role in the proximal tubules of the kidney, very likely in different channel complexes, and their function appears to only become important in conditions of physiological stress.

2.1.6. KCNQ1-KCNE1 in the Brain. Historically, the view has been that while KCNQ2-5 are neuronally expressed, KCNQ1 is not. This view has been challenged by the Noebels group, which reported expression of KCNQ1-KCNE1 channels in mouse brain, specifically in the somata of cells within pyramidal neurons (CA1-CA3 of the hippocampus), hilar interneurons, and in granule cells of the dentate gyrus. Outside the hippocampus, KCNQ1 immunoreactivity was detected in the neocortex, thalamus, dentate granule cells, and in glialike processes of the subcortical white matter tracts [134]. Furthermore, knockin into mouse neuronal populations of mouse equivalents (KCNQ1-A340E and KCNQ1-T311I) of two human KCNQ1 gene mutants associated with human Long QT syndrome (Romano-Ward Syndrome and JLNS, resp.) caused seizures [134]. The seizures then appeared to trigger cardiac arrhythmias in a putative mouse model of Sudden Unexplained Death in Epilepsy (SUDEP). The likely underlying mechanism of seizure-linked cardiac arrhythmia in these KCNQ1 mutant mice was aberrant cortical discharges, as these were often followed, within $200 \mathrm{~ms}$, by cardiac conduction abnormalities; in addition, the Noebels group was able to record, in one instance of SUDEP in a KCNQ1-T311I mutant mouse, a loss of brain wave activity associated with depressed respiratory rate. This progressed to a lethal slowing of the heart rate (bradycardia). There has been considerable resistance to the idea of KCNQ1 channels in neurons, even though in prior reports the evidence for and against was far from conclusive (see [134] for summary).

2.2. KCNQ1-KCNE2-Constitutively Active at Hyperpolarized Potentials despite Its Voltage Sensor. The effects and physiological role of KCNE2 modulation of KCNQ1 are in sharp contrast to those of KCNE1 on KCNQ1. No unitary current recordings or noise variance analysis of KCNQ1KCNE2 currents have been reported to date; macroscopic currents show a constitutively active yet low conductance channel [50], properties that suggest it will be incredibly challenging to reliably record recognizable unitary KCNQ1KCNE2 currents. The ability to remain open and presumably noninactivated appears to be essential for the diverse 
functions KCNQ1-KCNE2 serves in nonexcitable, polarized epithelial cells.

2.2.1. KCNQ1-KCNE2 in the Gastric Epithelium. In parietal cells within gastric glands of the stomach epithelium, apical KCNQ1-KCNE2 channels provide a $\mathrm{K}^{+}$recycling pathway to counteract $\mathrm{K}^{+}$influx through the apical gastric $\mathrm{H}^{+} \mathrm{K}^{+}$ATPase that acidifies the stomach lumen (Figure 5(a)) [84, 135, 136]. KCNQ1-KCNE2 must remain open at negative voltages (probably largely between -40 and $-20 \mathrm{mV}$ in parietal cells) and in the face of the extremely acidic extracellular environment of the gastric pits ( $\mathrm{pH} 2-3$ ). This constitutive activation is most likely achieved, at least in part, by KCNE2 favoring the activated conformation of the voltage sensor, as is known to occur with KCNE3 (see below). However, the KCNQ1 current augmentation in response to low extracellular $\mathrm{pH}$ is unique to channels formed with KCNE2. Homomeric KCNQ1 channels are inhibited by extracellular protons, right-shifting the voltage dependence of activation, slowing activation, and deactivation gating kinetics, while disrupting inactivation. KCNQ1-KCNE1 also shows inhibition but is less sensitive to $\mathrm{pH}$, whereas KCNQ1-KCNE2 current, crucially, is augmented by low $\mathrm{pH}$. This property, mediated by the extracellular N-terminus and neighboring portion of the transmembrane domain, is not a general feature of constitutively active KCNQ1 channels because KCNQ1-KCNE3 channels are largely voltage-independent and insensitive to $\mathrm{pH}$ (see below) [137, 138]. It is tempting to speculate that the unique $\mathrm{pH}$ dependence of KCNQ1-KCNE2 evolved because it gave a selective advantage in terms of greater ability to maintain proton secretion from the gastric pits for longer and thus more fully digest complex, protein-rich foods.

2.2.2. KCNQ1-KCNE2 in the Thyroid Epithelium. Interestingly, while mice lacking either KCNQ1 or KCNE2 cannot acidify their stomach lumen, these knockout mice can easily absorb normal mouse chow and reach the normal bodyweight of wild-type littermates by adulthood [139], while later in life, severe gastric hyperplasia and even neoplasia can occur [139]. However, early development of $\mathrm{Kcne}^{-/-}$pups can be impaired for other reasons. Thus, we discovered that mouse pups lacking Kcne2 exhibit abnormalities including prenatal mortality, growth retardation, alopecia, and cardiac hypertrophy [140]. These traits were more severe in pups from $\mathrm{Kcne}^{-/-}$dams; in fact, even wild-type pups from $\mathrm{Kcne}^{-/-}$dams exhibited this phenotype. We discovered that the molecular basis for this is that KCNQ1-KCNE2 is expressed in the basolateral membrane of thyrocytes and is required for normal production of thyroid hormone by the thyroid gland (Figure 5(b)) [140].

Also at the basolateral side of thyrocytes, the sodium iodide symporter (NIS) sequesters iodide in the thyroid gland, using the sodium gradient to facilitate influx of iodide ions $\left(\mathrm{I}^{-}\right)$[142]. KCNQ1-KCNE2 is required for efficient function of NIS in this fashion and thus for efficient $\mathrm{I}^{-}$ uptake. It seems that NIS can function adequately without KCNQ1-KCNE2 in, for example, young virgin adult mice, which appear normal and euthyroid. However, Kcne2 ${ }^{-/-}$ mice that are gestating or lactating are not able to produce sufficient thyroid hormone, presumably because of increased requirements, and the relative inability of the thyroid gland in these mice to take up sufficient iodide can be observed using positron emission tomography to track ${ }^{124}$ I movement $[140,143]$. Pups of $\mathrm{Kcne}^{-/-}$dams are severely affected, exhibiting early cardiac hypertrophy, growth retardation, and alopecia, largely because the dams' hypothyroidism impairs milk ejection. This can be rescued acutely by oxytocin injection of the dams or in the long term by thyroid hormone supplementation during gestation and lactation. $\mathrm{Kcne}^{-2^{--}}$pups surrogated to Kcne2 $2^{+/+}$dams after birth (i.e., separated from their mothers and instead allowed to suckle from wild-type dams) also develop normally because they have sufficient access to milk. Conversely, Kcne2 ${ }^{+/+}$pups surrogated to Kcne $2^{-l-}$ dams develop features synonymous with hypothyroidism [140].

The reason that NIS requires KCNQ1-KCNE2 for optimal function is currently under study, but several mechanistic insights have been drawn from a combination of in vitro and in vivo studies. First, KCNQ1-KCNE2 is not required for $\mathrm{I}^{-}$organification (the process of incorporation of $\mathrm{I}^{-}$ into thyroglobulin) but is needed for $\mathrm{I}^{-}$uptake. Second, KCNQ1-KCNE2 inhibition by the relatively specific KCNQ1specific antagonist (-)-[3R, 4S]-chromanol 293B impairs $\mathrm{I}^{-}$ sequestration by thyroid cells via $\mathrm{Na}^{+}$-dependent $\mathrm{I}^{-}$uptake by NIS but does affect $\mathrm{Na}^{+}$-dependent nicotinate uptake by the sodium-coupled monocarboxylate transporter (SMCT), using the FRTL-5 rat thyroid cell line in both cases as a model system. This finding suggests specificity of the effects of KCNQ1-KCNE2 on NIS and not simply an effect favoring maintenance of the whole-cell transmembrane $\mathrm{Na}^{+}$gradient for all $\mathrm{Na}^{+}$-dependent transporters. Third, KCNQ1 requires coassembly with KCNE2 for its role in the thyroid, evident from the combination of findings that $\mathrm{Kcne}^{-/-}$mice have similar thyroid hormone insufficiency to $\mathrm{Kcnq1}^{-/-}$mice [149] and that a current with the characteristics of KCNQ1KCNE2 (XE991 sensitivity combined with linear currentvoltage relationship) is evident in FRTL-5 cells. Fourth, protein expression of both KCNQ1 and KCNE2 in FRTL-5 cells is increased by thyroid-stimulating hormone (TSH) or its major downstream effector, cyclic adenosine monophosphate (cAMP) $[140,143]$.

2.2.3. KCNQ1-KCNE2 in the Choroid Plexus Epithelium. KCNQ1-KCNE2 channels are also expressed in the apical membrane of the choroid plexus epithelium, the bloodCSF barrier, and primary site of cerebrospinal fluid (CSF) production and secretion (Figure 5(c)) [150]. The effects of Kcnq1 gene deletion in mice have not yet been reported with respect to choroid plexus function, but $\mathrm{Kcne}^{-/-}$mice exhibit increased outward KCNQ1 current, hyperpolarized membrane potential, a switch in KCNQ1 localization (from apical to basolateral) and a subtle change in CSF chloride concentration (14\% increase) compared to $\mathrm{Kcne}^{+/+}$ mice. The increased KCNQ1 current can be explained by the effects of KCNE2 on KCNQ1 in vitro, which show 


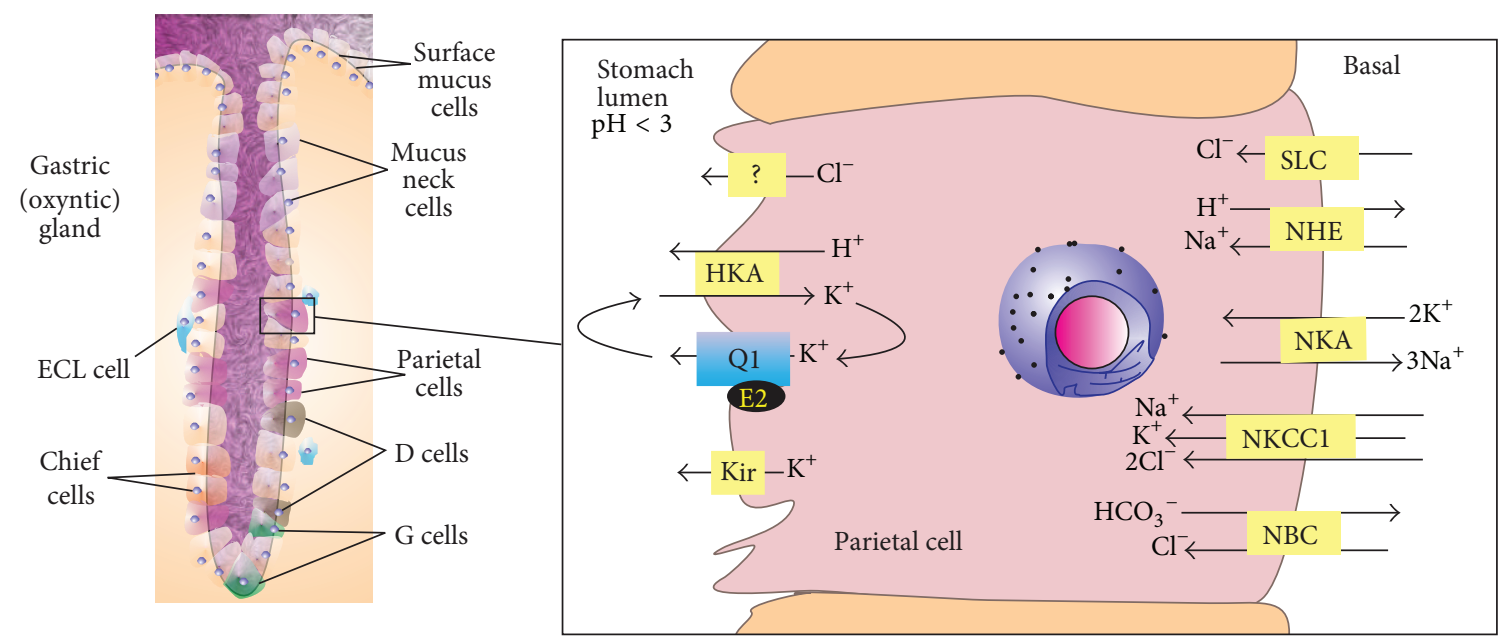

(a)

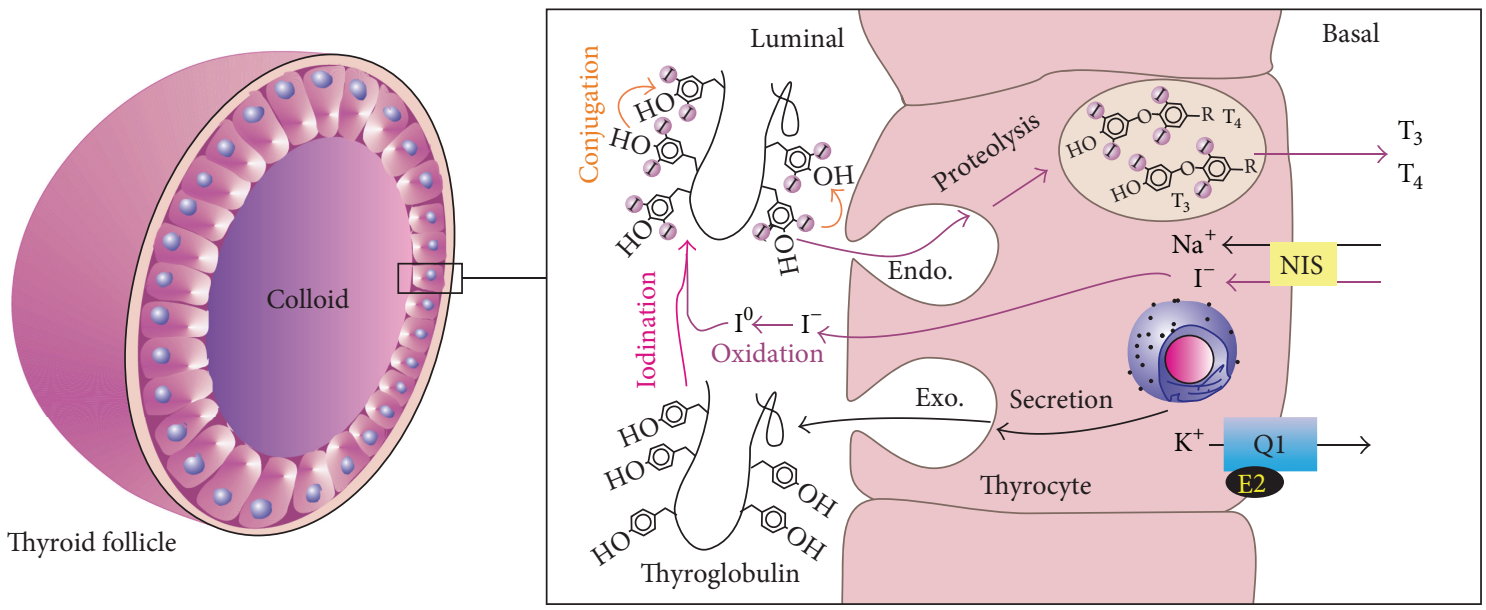

(b)

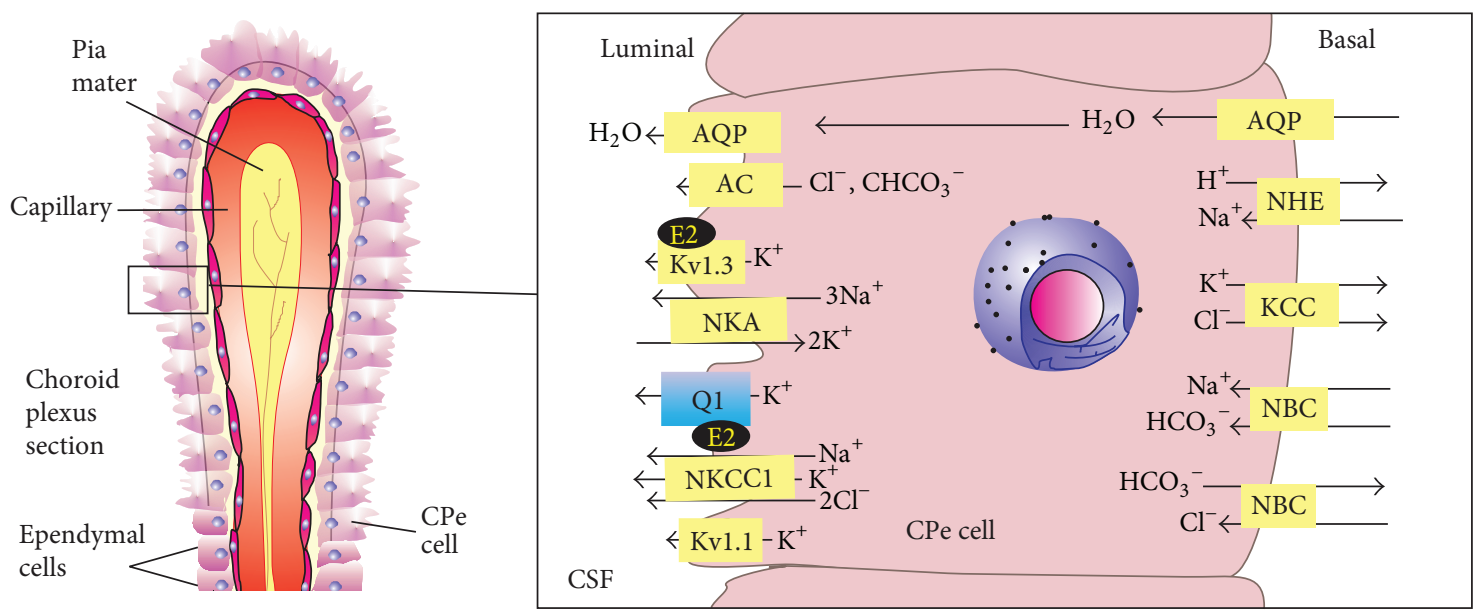

(c)

FIGURE 5: Examples of KCNQ1-KCNE2 location and function in polarized epithelia. (a) Left, representation of a gastric gland; right, the gastric $\mathrm{H}^{+} / \mathrm{K}^{+}$-ATPase requires a luminal $\mathrm{K}^{+}$recycling pathway for proton secretion and gastric acidification, formed by complexes of KCNQ1 (Q1) and KCNE2 (E2). (b) Left, representation of a thyroid follicle skirted by thyroid epithelial cells (thyrocytes); right, thyroid hormone ( $\mathrm{T}_{3}$ and $\mathrm{T}_{4}$ ) biosynthesis requires $\mathrm{I}^{-}$to pass across the thyrocyte from the blood into the colloid, where it is oxidized and organified by incorporation into thyroglobulin (iodination and conjugation). Channels formed by a complex of KCNQ1 and KCNE2, on the thyrocyte basolateral membrane, facilitate efficient function of the basolateral sodium iodide symporter (NIS). (c) Left, representation of the choroid plexus epithelium (CPe); right, KCNQ1 is regulated by KCNE2 in the CPe apical membrane. 
reduced macroscopic outwards currents despite constitutive activation (the basis for this macroscopic current reduction is not yet known) [150]. The switching of KCNQ1 to the basolateral side of the choroid plexus epithelium upon Kcne2 deletion is also observed in parietal cells [150] and is covered below in more detail in the KCNQ1 trafficking section. The neural consequences for mice of choroid plexus KCNQ1KCNE2 channel disruption are at time of writing under study in the author's lab. It should be noted that KCNE2 also modulates Kv1.3 (KCNA3) in the choroid plexus epithelium, and relative effects of Kcne2 deletion on the two $\alpha$ subunits were distinguished using pharmacologic agents (XE991 for KCNQ1; margatoxin for Kv1.3) [150].

2.2.4. KCNQ1-KCNE2 in the Heart. KCNE2 has also been proposed to modulate KCNQ1 in the heart, possibly by modulating or participating in complexes formed between KCNQ1 and KCNE1 [151-153]. Indirect evidence, that is, that KCNE2 gene variants increase KCNQ1-KCNE2 current, suggests the possibility for a role in atrial fibrillation and therefore in human heart for this subunit combination [80]. Unfortunately, because KCNQ1 is not significantly expressed in adult mouse heart, mouse studies have not been useful in elucidating how cardiac KCNQ1 is regulated by different KCNE subunits (and the same applies to ERG). However, KCNQ1 (and ERG) is expressed in neonatal mouse heart and future analyses could be directed at elucidating which KCNE subunit(s) regulates KCNQ1 in this model heart system, what are the effects of interaction and consequences of disruption, and how complex is the interplay between different KCNEs in regulating KCNQ1. These types of questions have been difficult to address in nontransgenic systems and we know very little about the potential dynamism of KCNQ1 regulation by KCNE and indeed other regulatory subunits in vivo. However, an understanding of these processes could lead to not just a picture of the biology of KCNQ1 that could apply to other channels, but also potentially it is an avenue for improved therapeutics-KCNEs can alter KCNQ1 pharmacology and could provide added specificity or even cell type selectivity $[21,154]$.

2.3. KCNQ1-KCNE3: A Constitutively Active "Kv" Channel. KCNE3 also renders KCNQ1 constitutively open and unlike with KCNE2 maintains a macroscopic outward current density at levels equivalent to or higher than those generated by homomeric KCNQ1 [49]. Thus far, the ability of KCNE2 and KCNE3 to convert KCNQ1 to a "leak" channel is unique among the S4 superfamily of voltage-gated ion channels: no other voltage-gated ion channels are known to be convertible (the leucine-rich repeat (LRR)-containing protein 26, LRRC26, and left-shifts activation of voltage- and $\mathrm{Ca}^{2+}$ activated $\mathrm{BK}$ channel gating by $-140 \mathrm{mV}$, but these heteromers are still closed at $-80 \mathrm{mV}[155,156])$. Likewise, KCNE2 and KCNE3 each interact with several other Kv channels but do not lock them open, although KCNE3 left-shifts the voltage dependence of Kv3.4 activation by $-45 \mathrm{mV}$, a considerable hyperpolarizing shift [20, 157-159]. KCNE3 appears to favor constitutive activation of KCNQ1 by locking open its voltage sensor rather than by directly locking open the pore independent of the voltage sensor $[92,160]$. Using site-directed mutagenesis, we identified critical KCNE3 residues at the membrane-proximal region of the extracellular portion of KCNE3 that likely interact with KCNQ1-S4 as part of this process [161]; the McDonald lab had previously discovered that residues in the KCNE3 transmembrane domain are also essential for KCNQ1-KCNE3 constitutive activation [162, 163]. Interestingly, heterologously expressed KCNQ1-KCNE3 channel currents typically exhibit a voltage-dependent fraction, and that fraction is proportionately much greater when expressed in mammalian cell lines including human embryonic kidney (HEK) cells than in Xenopus laevis oocytes $[159,162-164]$. This may arise from important regulatory differences or even different subunit compositions between the two types of expression system; we previously found that Xenopus oocytes express endogenous KCNE proteins that can impact electrophysiological studies of $\mathrm{Kv}$ channels $[96,165]$.

2.3.1. KCNQ1-KCNE3 in the Intestinal Epithelium. The bestestablished role for KCNQ1-KCNE3 channels is in the intestine; KCNQ1 colocalizes with KCNE3 in the basolateral membrane of colonic crypts $[49,166]$. Studies utilizing a $\mathrm{Kcne}^{-/-}$mouse line [166] confirmed the prior report [49] that KCNQ1-KCNE3 is required for regulation of cAMP-stimulated chloride secretion. Basolateral recycling of $\mathrm{K}^{+}$through KCNQ1-KCNE3 channels, together with the increased driving force generated by $\mathrm{K}^{+}$efflux through this heteromer, are thought to both promote electrogenic $\mathrm{Cl}^{-}$ secretion across the intestinal epithelium [104, 167, 168]. Kcne3 deletion in mice reduces intestinal epithelial $\mathrm{Cl}^{-}$ secretion without altering KCNQ1 localization or abundance, supporting a model in which the modification of KCNQ1 gating (conversion from voltage-dependent activation to constitutive activation) is a primary factor in the necessity of KCNE3 in colonic KCNQ1 channel complexes [166]. Thus, again, by locking KCNQ1 open, KCNE3 diversifies its functional capabilities and permits it to operate in a nonexcitable cell type. In this case, this involves provision of a constitutive drive toward the potassium equilibrium potential $\left(E_{\mathrm{K}}\right)$ that can be modulated by signaling elements in addition to and including voltage (despite being constitutively active, increased electrical driving force still increases voltage-independent currents, it just does so largely without altering their gating).

KCNE3 also adds a further level of complexity to the colonic current in that it is regulated by estrogen [169], which downregulates KCNE3 and thus increases the relative proportion of homomeric KCNQ1, which does not function so efficiently in nonexcitable cells because it requires cellular depolarization for efficient activation. Consequently, during the estrous cycle, the high levels of estrogen associated with proestrus cause water retention in female mammals partly by removing the capacity of KCNQ1 to operate (and thus facilitate cAMP-stimulated $\mathrm{Cl}^{-}$secretion) at negative voltages. Colonic crypts from male rat distal colon show higher KCNE3 expression and $>2$-fold higher association of KCNQ1 and KCNE3, than those from female rat. Estrogen 
actually causes dissociation of KCNE3 from KCNQ1 within a timescale of minutes $[148,170]$. Interestingly, mutation to alanine of the intracellular, membrane-proximal serine PKC phosphorylation site, and KCNE3-S82 blunted the effects of $17 \beta$-oestradiol on KCNQ1-KCNE3 in vitro and also caused rapid rundown [170]. We previously found that KCNE3S82 phosphorylation is crucial for KCNE3 modulation of KCNC4 (Kv3.4) activation gating [158], suggesting that the importance of this KCNE3 site and its role in control of gating through phosphorylation are conserved between different channel complexes.

\subsubsection{KCNQ1-KCNE3 in the Mammary Epithelium. KCNQ1-} KCNE3 channels have also been implicated to play a role in the mammary epithelium [171]. Pharmacological inhibition of KCNQ1 channels in the human mammary epithelium cell line MCF-7 abolishes the ability to respond to hyposmotic stress initiated by switching from an isosmotic to a hyposmotic extracellular solution. This ability is likely to be highly important in mammary epithelia because milk contains a high $\mathrm{K}^{+}$concentration and also comprises high concentrations of impermeable solutes including lactose. KCNQ1 appears to be localized at the apical membrane of mammary epithelial cells, and a KCNQ1-like current in MCF7 cells is activated by hyposmotic extracellular solutions. This was recapitulated in baby hamster kidney cells with KCNQ1 heterologously expressed alone or with KCNE3, which is also detected in MCF-7 cells [171].

It is also possible that KCNQ1 interacts with other KCNE subunits in mammary epithelium; KCNE1 and KCNE2 are both present [171]. We previously found that $\mathrm{Kcne}^{-/-}$mice have a milk ejection defect that was able to be rescued acutely by oxytocin injection, but this defect was attributable to the hypothyroidism exhibited by lactating $K c n e 2^{-/-}$dams as it was preventable with thyroid hormone treatment [140]. At present, it is reasonable to assume that KCNQ1 is required for mammary epithelial cell volume regulation, probably via $\mathrm{K}^{+}$secretion. In mammary epithelial cells, KCNQ1 may coassemble with one or more of the KCNE subunits, but KCNQ1 does not appear to require this coassembly for cell volume regulation, at least in heterologous expression experiments $[171,172]$.

2.3.3. KCNQ1-KCNE3 in the Airway Epithelium. As in the colonic crypts, Kcne3 deletion in mice impairs transepithelial electrogenic $\mathrm{Cl}^{-}$secretion in murine trachea, most likely because of conversion of constitutively active, cAMPsensitive KCNQ1-KCNE3 back to homomeric and voltagedependent KCNQ1 [166]. Several studies have now indicated a role for KCNQ1 in the basolateral membrane of the airway epithelium. Accumulating evidence, culminating in the description of the Kcne3 null mouse, strongly suggests it is again the KCNQ1-KCNE3 complex that is required for sufficient activity of a basolateral $\mathrm{K}^{+}$current essential for normal cAMP-stimulated $\mathrm{Cl}^{-}$secretion $[166,173-175]$. In the airways, this $\mathrm{Cl}^{-}$secretion is important for normal mucous production and secretion, hence, the overproduction defect in mucus secretion in individuals with cystic fibrosis-linked
CFTR channel mutations [176]. Although KCNE1 was previously suggested to regulate KCNQ1 in airway epithelia, in a subsequent paper three lines of evidence were presented favoring, instead, a role for KCNE3 in regulating KCNQ1 [173]. First, Kcne1 null mice did not present with a defect in tracheal epithelial $\mathrm{Cl}^{-}$secretion. Second, KCNQ1 but not KCNE1 was detected in the airway epithelium basolateral membrane. Third, KCNE3 and KCNQ1 message but not KCNE1 message were detected in tracheal epithelial cells by RT-PCR. In this study, it was suggested that basolateral KCNQ1-KCNE3 not only regulates $\mathrm{Cl}^{-}$secretion, but also supports $\mathrm{Na}^{+}$reabsorption, in mouse airways [173]. An interesting side note to these findings is that a human genomic DNA sequence variant $84 \mathrm{~kb}$ upstream of KCNE2 has been associated with lung dysfunction [177]. We recently detected Kcne2 transcript expression in whole lung preparations from wild-type mice using tissue from $\mathrm{Kcne}^{-/-}$mice as a negative control ( $\mathrm{Hu}$ et al., submitted), and others have reported KCNE2 expression in the human airway cell line Calu-3 [178]. The potential role for KCNQ1-KCNE2 in lung epithelia is unknown but targeted for future study.

2.4. KCNQ1-KCNE4. KCNE4 is expressed in human and mouse heart, brain, skeletal muscle, uterus, testis, kidney, liver, lymphocytes, and placenta [179-181]. KCNE4 possesses the longest intracellular domain among the mammalian KCNE family [179], suggestive of a role for this domain in mediating interactions with intracellular regulatory proteins or in sensing other aspects of the intracellular milieu. Mouse and human variants of KCNE4 are reported to strongly (>90\%) inhibit KCNQ1 activity in heterologous coexpression experiment in Xenopus laevis oocytes, as assayed by two-electrode voltage clamp [180]. The finding that human KCNE4 inhibits KCNQ1 was challenged in a study in which the authors found, instead, moderately slowed activation kinetics [182]. A subsequent response by the authors of the original KCNQ1-KCNE4 inhibition paper refuted these contradictory suggestions and reaffirmed the inhibitory role of KCNE4 with KCNQ1 in the absence of activation kinetic effects [183]. Bendahhou and colleagues also found inhibition of KCNQ1 by KCNE4 using patch-clamp analysis of currents after heterologous coexpression in COS cells [184].

Strikingly, the inhibitory effect of KCNE4 was canceled with the introduction of a naturally occurring gainof-function KCNQ1 mutation (S140G) linked to human atrial fibrillation. In complexes with S140G-KCNQ1, KCNE4 removed the constitutive activation imposed by the S140G mutation, giving heteromers with slowed activation but not peak current inhibition (in fact, increasing peak current at depolarized potentials) [184]. These insights suggest KCNE4 may operate by dramatically right-shifting the voltage dependence of activation of KCNQ1, that is, by stabilizing the closed state, but may even have positive effects on, for example, KCNQ1 conductance that are normally masked by the inhibitor effect that likely involves gating changes.

The possibility remains that KCNQ1-KCNE4 complexes exist in cardiac myocytes, for example, and that they provide a "repolarization reserve" current that is relatively inactive until 
turned on in response to an environmental or physiological stress stimulus. It has also been reported that KCNE4 can be associated with the "established" human ventricular $I_{\mathrm{Ks}}$ channel subunit combination of KCNQ1-KCNE1, forming a tripartite channel complex; in this study no changes in KCNQ1 surface expression were observed upon KCNE4 coexpression, further supporting an inhibitory effect arising from gating regulation rather than altered trafficking [181].

In particular, the intracellular domain of KCNE4 is important for its inhibition of KCNQ1, although the transmembrane domain is also required for the $\mathrm{C}$ terminus to perform this role [185]. The importance of the intracellular domain also tallies with an inhibitory effect based upon gating because the $\mathrm{C}$ terminal domain of KCNE1, the most highly studied KCNE subunit, has been shown to interact with $[186,187]$ and/or alter the environment of the S4-S5 linker (that communicates voltage sensor $\mathrm{S} 4$ movement to the channel activation gate) $[97,186,188]$ of KCNQ1 to modulate voltage sensor response to depolarization. In KCNQ1-KCNE1 complexes this causes right-shifted voltage dependence and dramatic slowing of activation; some version of this type of regulation may occur in KCNQ1-KCNE4 complexes, with an effect exaggerated to the point that it causes inhibition within the typical physiological voltage range and also the slightly wider range typically used in voltage clamp experiments (e.g., $-120 \mathrm{mV}$ to $+60 \mathrm{mV}$ ).

Subsequent additional studies from the George lab revealed further insights into KCNQ1 control by KCNE4, specifically that KCNE4 can form a complex with the cytoplasmic $\mathrm{Ca}^{2+}$ sensor calmodulin, a known regulator of KCNQ1 (see below) in a $\mathrm{Ca}^{2+}$-dependent fashion, requiring a juxtamembrane tetraleucine motif in KCNE4. Importantly, disruption of this interaction diminishes the inhibitory effect of KCNE4 on KCNQ1 [189]. Because the KCNE4-calmodulin interaction is $\mathrm{Ca}^{2+}$ dependent, reduction of intracellular $\mathrm{Ca}^{2+}$ concentration is one candidate mechanism for relieving KCNE4 inhibition of KCNQ1 and thus increasing current through the latter to increase repolarizing current as suggested above.

2.5. KCNQ1-KCNE5. As with the other four known human KCNE subunits, KCNE5 (originally named KCNE1-like or KCNE1L [190], and also termed MiRP4) has been detected in human heart and can regulate KCNQ1 in heterologous expression studies $[184,191]$. KCNE5 right-shifts the voltage dependence of KCNQ1 activation to $>140 \mathrm{mV}$ more positive, which would ensure that KCNQ1-KCNE5 channels could contribute little to the channel activity of nonexcitable or excitable cells under physiological conditions. The activation $\mathrm{K}^{+}$rate of KCNQ1-KCNE5 channels is slow like that of KCNQ1-KCNE1 but with different temperature dependence [191]. Putative associations of KCNE5 gene variants with inherited arrhythmia syndromes hint at a potential role for KCNQ1-KCNE5 complexes in the heart [78, 79, 192], although KCNE5 could equally modulate one or more other $\mathrm{Kv}$ channels in vivo. In vitro, it does not alter the properties of other KCNQ channels or hERG, indicating some degree of KCNQ1-specificity [191].
One can imagine that a role for KCNQ1-KCNE5 channels in vivo would require either another subunit, or a distinct regulatory mechanism, to render them functional at physiological voltages. In fact, one role KCNQ1-KCNE5 might play is to act as a dampener for KCNQ1-KCNE1 channels, the latter being inhibited by KCNE5 coexpression in vitro [78]. Interestingly, atrial fibrillation-associated KCNE5 mutant L65F was unable to suppress KCNQ1-KCNE1 current in vitro in parallel experiments, suggesting this indirect gain-offunction of native $I_{\mathrm{Ks}}$ as a possible molecular mechanism for the atrial action potential duration shortening associated with idiopathic atrial fibrillation [78].

One likely alternative partner for KCNE5 is Kv4.3, which generates the transient outward $\mathrm{K}^{+}$current $\left(I_{\mathrm{to}}\right)$ apparent at the onset of human cardiac myocyte repolarization. Brugada syndrome is a potentially lethal ventricular arrhythmia most commonly associated with voltage-gated sodium channel loss-of-function but also linked to gain of function of $I_{\text {to }}$ components. While wild-type KCNE5 moderately inhibits and speeds the inactivation of currents passed by $\mathrm{Kv} 4.3$ heterologous expressed in vitro in combination with the cytosolic KChIP2 ancillary subunit (a partner of $\mathrm{Kv} 4$ channels in mammalian heart and brain), Brugada syndromeassociated with KCNE5 mutants eliminated this impairment and quickening of inactivation [193]. As with all the KCNE subunits, regulation of KCNQ1 is likely just one piece in the puzzle of the complex role of KCNE5 in vivo; likewise, even cardiac syndromes linked to KCNE5 gene variants will probably ultimately be found to arise from disruption of multiple channel types, potentially in multiple tissues.

\section{Regulation of KCNQ1 by Non-KCNE Protein Subunits and Other Agents}

Aside from the molecular toolkit for KCNQ1 functional diversification provided by the $K C N E$ gene family, there are a host of other influences directing KCNQ1 channel activity. Some of the more prominent ones are described here.

3.1. KCNQ1 and Genomic Imprinting. Parent-of-origin effects can occur when genes of only one allele are expressed in the offspring, in an epigenetic phenomenon referred to as genomic imprinting. Genomic imprinting involves DNA methylation and histone modulation to facilitate monoallelic expression of a gene or cluster of genes, often in a tissuespecific fashion. KCNQ1 lies within a region on human chromosome 11p15, near the IGF2 gene, that is of much interest to epigeneticists as it is affected in Beckwith-Wiedmann Syndrome (BWS). BWS, caused by disrupted imprinting, is a disease associated with early developmental overgrowth and increased risk of cancer, especially within the first seven years of life.

KCNQ1 is imprinted in most tissues, being expressed only from the maternal allele [194, 195]. The post-midgestation heart is thought to be an exception, which could explain why BWS is typically not manifested as LQTS (although rarely patients can exhibit features of both disorders). However, it is important to note that biallelic expression of KCNQ1 in 
the heart has thus far only been demonstrated in mice [196]. In human fetal cardiac tissue, KCNQ1 expression was not detectable in two of six samples [194]. Examining human lymphoblastoid cell lines, Serre and colleagues found reduced KCNQ1 expression on the paternally imprinted allele [197].

Several genes within the region on chromosome 11p15 affected in BWS are affected by loss of silencing, causing them to be expressed on both paternal alleles instead of just one. KCNQ1OT1 (also termed LIT1 for Long QT intronic transcript 1) is a paternally expressed noncoding RNA expressed from an intron within KCNQ1 in the antisense direction [194]. The KCNQ1OT1 promoter region overlaps with the differentially methylated region KvDMR1 (sometimes referred to as imprinting cluster 2 or IC2). KCNQ1OT1 can only be expressed from the unmethylated paternal allele. KCNQ1OT1 normally silences several neighboring genes; therefore, abnormal methylation in this region alters expression of both KCNQ1OT1 and the genes it regulates. Loss-ofimprinting of KCNQ1OT1 is considered the most common genetic perturbation in BWS [194]. The mechanism by which KCNQ1OT1 silences its target genes involves recruitment of both chromatin and DNA-modifying proteins including the polycomb proteins EZH2 and SUZ12 [198]. For a comprehensive review of KCNQ1OT1 gene silencing mechanisms; see [199].

Interestingly, early stage imprinting of KCNQ1 itself does not require expression of KCNQ1OT1. In fact, both lose their imprinted expression in the heart at around the same time in development. It is known, however, that KCNQ1OT1 absence causes inappropriate KCNQ1 overexpression later in the development of the heart [200].

\subsection{Extracellular Potassium Directly Modulates KCNQ1 Activ-} ity. Aside from its obvious role in the electrochemical gradient influencing KCNQ1 function, extracellular potassium was found to inhibit KCNQ1 activity, beyond that predicted by the Goldman-Hodgkin-Katz flux equation [201]. This inhibition occurs in a physiologically important range, with an $\mathrm{IC}_{50}$ of $6 \mathrm{mM}$, which in human serum would constitute mild hyperkalemia. The mechanism for this inhibition is an increase in the proportion of KCNQ1 channels in the inactivated state (a state in which the pore is technically open, but nonconducting; that is, the activation gate can be open in this state, but the inactivation gate is closed). Channels formed by KCNQ1 and either KCNE1 or KCNE3 do not inactivate; accordingly, these heteromers are insensitive to the inhibitory effects of extracellular $\mathrm{K}^{+}$. Thus, extracellular $\mathrm{K}^{+}$ may play a physiological role in regulation of some channels formed with KCNQ1, by promoting and/or stabilizing the inactivated state [201]. This could be potentially useful in limiting $\mathrm{K}^{+}$efflux (beyond the effects of reduced electrochemical gradient) in scenarios in which the extracellular space is $\mathrm{K}^{+}$replete, such as in the deep pits of oxyntic glands in the gastric lumen, into which $\mathrm{K}^{+}$is recycled from parietal cells by the KCNQ1-KCNE2 complex. Interestingly, like homomeric KCNQ1 but unlike KCNQ1-KCNE1 and KCNQ1KCNE3 channels, KCNQ1-KCNE2 is reportedly inhibited by extracellular $\mathrm{K}^{+}$[201]. KCNQ1 channels are also inhibited by extracellular protons, but this topic is covered above in the section on KCNQ1-KCNE2, in which it is described how different KCNE subunits each differentially tune the $\mathrm{pH}$ dependence of KCNQ1.

3.3. Phosphatidylinositol 4,5-Bisphosphate $\left(\mathrm{PIP}_{2}\right)$ Is Important for $I_{K s}$ Activation. $\mathrm{PIP}_{2}$ is generated primarily from phosphatidylinositol 4-phosphate, which itself is enriched in the membrane of the Golgi apparatus. This conversion is catalyzed by type I phosphatidylinositol 4 phosphate 5 kinases. PIP $_{2}$ is actually a relatively minor, acidic phospholipid component of the plasma membrane, but the realization of its importance in cell signaling has ensured that a major research field has built up around studying its physiological roles. One of the most interesting and highly researched areas is $\mathrm{PIP}_{2}$ regulation of ion channel function. $\mathrm{PIP}_{2}$ is now considered to be an essential cofactor for ion channels as diverse as epithelial $\mathrm{Na}^{+}$channels, TRP channels, Kv channels, and inward rectifiers.

All five members of the KCNQ family are directly activated by $\mathrm{PIP}_{2}$ applied to the cytoplasmic face [202]. Many channel types, including KCNQ1-KCNE1 channels, exhibit rundown or loss of activity over time, when studied in excised patches (in which a patch of membrane containing the channels is pulled off the cell using a microelectrode and recorded from "off-cell"). Cytosolic application of $\mathrm{PIP}_{2}$ to KCNQ1-KCNE1 channels in off-cell mode has been shown to dramatically slow this rundown, slowing deactivation kinetics and left-shifting the voltage dependence of activation such that channels can open more easily at negative voltages [203]. It appears that PIP $_{2}$ stabilizes one or more open states of KCNQ1-KCNE1, as is seen for other Kv channels including hERG [204] and also, for example, $\mathrm{K}_{\mathrm{ATP}}$ channels [205].

$\mathrm{PIP}_{2}$ regulation of KCNQ1-KCNE1 may also mediate the effects of cardiac arrhythmia-associated gene variants. Some LQTS-associated KCNQ1 mutations can decrease the $\mathrm{PIP}_{2}$ sensitivity of KCNQ1-KCNE1, thus preventing $\mathrm{PIP}_{2}$ dependent augmentation of $I_{\mathrm{Ks}}$, which may be required to maintain timely ventricular repolarization [206]. Differential $\mathrm{PIP}_{2}$ sensitivity of KCNQ1-KCNE1 channels, dependent upon $\mathrm{Mg}^{2+}$ and polyamines within the cell, implicates a role for $\mathrm{PIP}_{2}$ modulation in sensing the local environment of KCNQ1KCNE1 and facilitating a response of the channel to osmotic stress. In this way, $\mathrm{PIP}_{2}$ is probably important for the known osmosensitivity of KCNQ1 in both excitable cells such as cardiac myocytes and in nonexcitable, polarized epithelial cells [207].

KCNE1 potently modulates the interaction of $\mathrm{PIP}_{2}$ with KCNQ1, increasing KCNQ1 sensitivity 100-fold and thereby augmenting baseline current. A cluster of basic residues in the KCNQ1 intracellular juxtamembrane region are important for the effect (through either $\mathrm{PIP}_{2}$ binding and/or an allosteric effect). As with KCNQ1 itself, LQTS-associated KCNE1 mutations in this region can impair the ability of KCNE1 to increase KCNQ1-KCNE1 PIP 2 sensitivity and this may contribute to the disease etiology [208]. Interestingly, KCNQ3 channel sensitivity to drugs including epilepsy medication retigabine is modulated by $\mathrm{PIP}_{2}$ [209]. Further work is required to investigate whether similar effects apply to KCNQ1-KCNE1 and drugs such as the chromanols, 
but, conversely, hexachlorophene (the active component in pHisoHex) has been shown to act as an agonist by stabilizing the KCNQ1-KCNE1 open state and can also rescue LQTS mutants that are thought to impair function by reducing PIP $_{2}$ binding affinity [210].

3.4. Yotiao Acts as a Scaffold to Assemble a Macromolecular Signaling Hub around KCNQ1. Yotiao, the smallest splice variant of the AKAP9 family, is an A-kinase anchoring protein-one of a family of proteins that each serve as scaffolds for macromolecular signaling complexes comprising protein kinase A (PKA) and other proteins. These complexes act as hubs to integrate different modes of cellular signals. In the case of KCNQ1-KCNE1, in vivo in cardiac myocytes this channel heteromer is part of a hub formed by direct interaction with Yotiao, PKA, protein phosphatase1, phosphodiesterase 4D3 (PDE4D3), and adenylyl cyclase 9 (AC9) [211-213]. Without Yotiao, $I_{\mathrm{Ks}}$ is unable to respond to sympathetic stimulation, which in the context of the heart would mean an absence of the capacity to respond to increased output demands arising from physical activity or stress via autonomic nervous system signaling. Yotiao can both directly alter channel function and also coordinate the actions of other proteins upon KCNQ1-KCNE1, by virtue of its role as a scaffold [214]. Emphasizing the importance of Yotiao in cardiac $I_{\mathrm{Ks}}$ complexes, a Yotiao sequence variant that impairs interaction with KCNQ1 and ablates $I_{\mathrm{Ks}}$ responsiveness to cAMP prolonged the ventricular action potential in silico and caused human LQTS [215]. Similarly, the KCNQ1-G589D mutation, also associated with LQTS, disrupts the ability of Yotiao to target PKA and protein phosphatase-1 to KCNQ1. This mutant does not impair in silico ventricular myocyte repolarization in a simple model at baseline but does impair repolarization and induce transient after depolarizations when beta-adrenergic stimulation is included in the computer model [216].

3.5. Calmodulin Is Important for KCNQ1 Folding and Tetramerization. As is the case for the M-current generating KCNQ2-KCNQ3 channels [217], the cytosolic $\mathrm{Ca}^{2+}$-binding protein and $\mathrm{Ca}^{2+}$ signaling mediator, calmodulin, is also important for KCNQ1 function and even assembly. Thus, calmodulin interaction is required for correct folding and functional assembly of KCNQ1 tetramers [218, 219]; LQTSassociated mutations that disrupt calmodulin interaction prevent functional tetramer formation in a dominant-negative fashion. Calmodulin also relieves KCNQ1 inactivation; this process requires $\mathrm{Ca}^{2+}$ binding, thus linking KCNQ1 channel activity to cytosolic $\mathrm{Ca}^{2+}$ concentration. Reduction of intracellular $\mathrm{Ca}^{2+}$ to below physiological levels causes current amplitude reduction and also an increase in inactivation in homomeric KCNQ1, whereas KCNQ1-KCNE1 channel currents are similarly reduced but without the increase in inactivation [218]. $\mathrm{Ca}^{2+}$-bound calmodulin also left-shifts the voltage dependence of $I_{\mathrm{Ks}}$ activation, contributing to its activity augmenting effects [219].

The proximal half of the KCNQ1 carboxyl terminus is required for calmodulin binding, each subunit of the KCNQ1

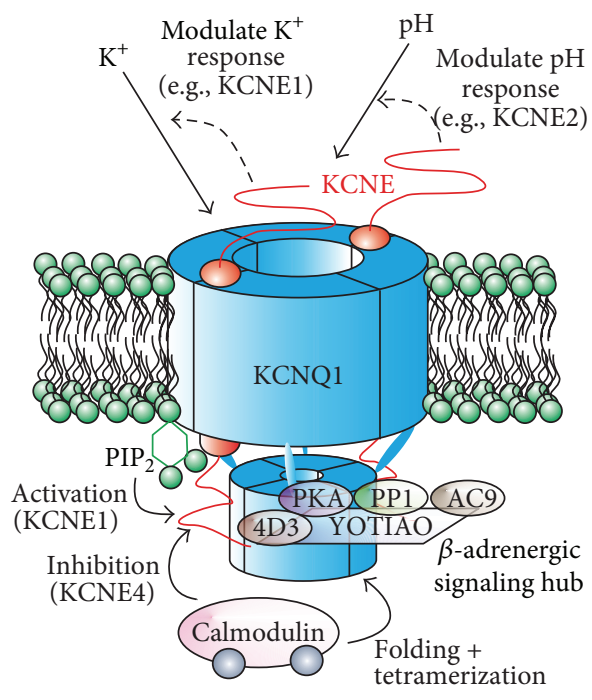

FIGURE 6: Multimodal regulation of KCNQ1. Cartoon summarizing non-KCNE regulatory influences on KCNQ1 and how KCNE subunits influence these processes, as described in Section 3. 4D3, phosphodiesterase PDE4D3; AC9, adenylyl cyclase 9; PKA, protein kinase A; PP1, protein phosphatase 1.

tetramer binding one calmodulin subunit, with complex formation important for correct channel folding. The distal half of the KCNQ1 carboxyl terminus appears to be important for channel tetramerization, utilizing a tandem coiled-coil mechanism. This is thought to involve the formation of a dimeric coiled-coil that then self-associates to form a dimer of dimers, and also assembly of an outer, parallel tetrameric coiled-coil. These two coiled-coils facilitate distal C-terminus tetramerization to seed formation of the functional KCNQ1 channel tetramer [220]. This is in contrast to the majority of $\mathrm{Kv}$ channels, in which the $\mathrm{N}$-terminal region tetramerization domain (T1 domain) is critical for tetramerization, probably by bringing together the same subfamily Kv $\alpha$ subunits to increase local concentration of the $\alpha$ subunits and thus seed subsequent transmembrane domain tetramerization [221]. As mentioned above, KCNE4 can also interact with calmodulin and this is essential for the ability of KCNE4 to inhibit KCNQ1 activity [189]. Also of note, KCNQ1 is regulated by direct nitrosylation of Cys445 in response to nitric oxide, but in a calmodulin-dependent manner; this could mediate the response of $I_{\mathrm{Ks}}$ and therefore the ventricular myocyte action potential, in vivo, to hormonal influence or changes in intracellular $\mathrm{Ca}^{2+}$ [222]. Clearly, KCNQ1 is subject to a wide array of regulatory influences, many of them direct and absolutely required for channel formation and normal activity in vivo (Figure 6).

\section{KCNQ1 Trafficking}

4.1. RAB-Mediated Exocytosis and Recycling of KCNQ1KCNE1. The processes governing how, where, and for how long ion channels travel to and remain at their site of action are of equal importance as that of their functional attributes 
once in situ. It is worth mentioning that the majority of Long QT-associated mutations in the hERG potassium channel gene, $\mathrm{KCNH} 2$, are thought to impair repolarization not by direct gating or conduction loss but by protein folding abnormalities, protein instability, and/or impaired surface trafficking [223, 224]. This is not thought to be the case for KCNQ1, but nevertheless there are a variety of cardiac arrhythmia-associated mutants in KCNQ1 known to impair trafficking and probably thus delay myocyte repolarization. Elements of the secretory pathway that facilitate trafficking of KCNQ1 from recycling endosomes back into the plasma membrane of cardiac myocytes have been dissected and found to involve the small GTPase RAB11, while a pathway mediating KCNQ1 endocytosis from the membrane into early endosomes involves RAB5 [144].

Important in mediating physiological responses to stress, the serum glucocorticoid kinases (SGKs) are activated by stress hormones such as the glucocorticoid cortisol through the hypothalamic-pituitary-adrenal axis and then act downstream to activate other proteins, including the KCNQ1 potassium channel. SGK1-3 all activate KCNQ1-KCNE1 channels when expressed in Xenopus oocytes, independent of endogenous $\mathrm{Na}^{+} / \mathrm{K}^{+}$ATPase activity [225]. An important underlying mechanism for SGK1 augmentation of KCNQ1-KCNE1 current is enhancement of channel exocytosis by the small GTPase RAB11. By increasing insertion of KCNQ1-KCNE1 channels into the plasma membrane, SGK1 can increase the repolarizing force in human ventricular myocardium, thus responding to stressful stimuli by shortening the QT interval and minimizing cardiac myocyte $\mathrm{Ca}^{2+}$ overload. SGK1 is thought to achieve this augmentation by activating PIKfyve, a PI(5)kinase, generating $\mathrm{PI}_{(3,5)} \mathrm{P}_{2}$, which enhances RAB11dependent KCNQ1-KCNE1 surface expression [144]. In contrast, KCNQ1-KCNE3 channels are insensitive to modulation by SGK1-3, at least in Xenopus oocyte expression studies [226]. Several residues on KCNE1 have been found to be important for SGK modulation of KCNQ1-KCNE1 complexes, and LQTS-associated mutations in KCNQ1 (Y111C and L114P) and KCNE1 (e.g., D76N) can reverse the normal effects of SGK1 on KCNQ1-KCNE1 activity, causing SGK1induced $I_{\mathrm{Ks}}$ downregulation arising from disrupted RAB11dependent recycling [145].

Similarly, in resting parietal cells, the majority of KCNQ1 was found to be localized to the RAB11-positive compartment, in contrast to the gastric $\mathrm{H}^{+} / \mathrm{K}^{+}$ATPase which was located in tubulovesicles. Upon parietal cell activation both proteins, however, relocated to the apical secretory canaliculi, sufficiently close to one another for robust Förster resonance energy transfer (FRET) [227]. Thus, RAB11-dependent, dynamic exocytosis of KCNQ1 in response to specific stimuli is common to cardiac myocytes and at least one polarized epithelial cell type.

4.2. Clathrin-Mediated Endocytosis of KCNQ1-KCNE1. As with other membrane proteins, ion channels including KCNQ1 have a finite lifespan at the cell surface and then are internalized either for recycling or degradation. There are three primary known mechanisms for KCNQ1 internalization in cardiac myocytes, one that is mediated by residues within KCNQ1 (involving RAB5 and described in the previous section), one that is mediated by residues within KCNE1 when the two form heteromeric complexes (described in this section), and one involving ubiquitylation (described in the next section).

We previously discovered a KCNE1-dependent internalization mechanism for KCNQ1 in vitro and confirmed its occurrence in isolated guinea pig ventricular myocytes [146]. This finding paved the way for a molecular solution to a 2-decade-old puzzle regarding the regulation of cardiac $I_{\mathrm{Ks}}$ by protein kinase $\mathrm{C}(\mathrm{PKC})$. We initially found that coexpression of KCNQ1 with a dominant-negative mutant (K44A) of the GTPase dynamin 2, essential for pinching-off of clathrin-coated pits during endocytosis, had no effect on homomeric KCNQ1 current or localization, in COS-7 cells. In contrast, K44A-dynamin dramatically increased KCNQ1KCNE1 currents and caused protein accumulation at the cell surface. This suggested that KCNE1 was coordinating clathrin-mediated endocytosis of KCNQ1-KCNE1 channels, a dynamin-dependent process.

A combination of three motifs on the intracellular Cterminal domain of KCNE1 was found to be necessary and sufficient to coordinate clathrin-mediated endocytosis of KCNQ1-KCNE1. This trio comprised DPFNVY (reminiscent of other AP-2 binding motifs involved in clathrin-mediated endocytosis [228]), consensus SH3-binding domain motif PSP [229], and a consensus serine phosphorylation site at serine 103. Mutation of either of the first two consensus sites reduced the amount of channel protein internalization; mutation of S102 to alanine impaired clathrin-mediated endocytosis of KCNQ1-KCNE1 whereas an aspartic acid preserved the ability of KCNE1 to coordinate KCNQ1 endocytosis. Mutation of all three sites at once prevented clathrin-mediated endocytosis of KCNE1 and KCNQ1-KCNE1 complexes [146].

Interestingly, in two prior papers, a serine phosphorylation site (serine 102) had been described in human, mouse and rat KCNE1 but not guinea pig KCNE1, which bears an asparagine at the equivalent position. S102 was required for PKC-dependent inhibition of current generated, in Xenopus laevis oocytes, from heterologously expressed rat or mouse KCNE1 and endogenous oocyte KCNQ1 (which was not discovered in man or frog until 1996) [230, 231]. Following our discovery of the requirement for KCNE1 in KCNQ1KCNE1 clathrin-mediated endocytosis [146], we were able to demonstrate, utilizing S102A and D mutants, PKC activators and both functional and imaging assays that PKC-dependent inhibition of KCNQ1-KCNE1 via S102 occurs by virtue of increased clathrin-mediated endocytosis [147], when S102 is phosphorylated. We also confirmed this process occurs in neonatal mouse myocytes. The finding that endocytosis was behind the PKC-dependent $I_{\mathrm{Ks}}$ inhibition tallied well with the slow time course of the latter, which was difficult to rationalize by purely "biophysical" means such as gating or conductance effects.

4.3. Nedd4 and USP2 Regulation of KCNQ1. KCNQ1 and KCNQ1-KCNE1 heteromers are also regulated by Nedd4/ Nedd4-like ubiquitin protein ligases, both when heterologously expressed in HEK cells and in guinea pig cardiac 
myocytes. Nedd4-2, which is the most highly cardiac enriched of the Nedd 4 family, interacts with a PY motif in the distal C-terminal domain of KCNQ1. This interaction promotes KCNQ1 and KCNQ1-KCNE1 channel ubiquitylation, leading to channel internalization from the plasma membrane and ultimately degradation of the internalized channel protein [232]. Conversely, the deubiquitylating enzymes ubiquitin-specific protease 2 (USP2) isoforms 45 and 69 counteract the effects of Nedd4-2, partially shielding KCNQ1 from Nedd4-2-mediated covalent attachment of ubiquitin moieties. The result is partial prevention of Nedd4-2 reduction in KCNQ1-KCNE1 current density and restoration of KCNQ1 membrane expression [233].

4.4. KCNE Subunits and Polarized Trafficking of KCNQ1. The polarized or targeted expression of KCNQ1 to specific cellular compartments is essential for normal function of those cells and is therefore expected to be tightly and dynamically controlled. In polarized epithelial cells, KCNQ1 localization has thus far always been localized to either one side or the other (apical or basolateral), although its polarity varies between each cell type. For example, as discussed above, in parietal cells KCNQ1-KCNE2 channels are apically expressed, a position from which they can return potassium ions to the stomach lumen after these ions have entered through the apical $\mathrm{H}^{+} / \mathrm{K}^{+}$ATPase during gastric acidification [135, 136, 168]. Similarly, KCNQ1-KCNE2 is expressed on the apical side of the choroid plexus [150]. In contrast, KCNQ1-KCNE3 complexes are basolaterally positioned in colonic crypts and airway epithelia, where they regulate cAMP-stimulated chloride secretion [166]. The emerging pattern would appear to be differential targeting of KCNQ1 dependent on which KCNE subunit it partners, but the situation is more complicated than that. In thyroid epithelial cells, for example, KCNQ1-KCNE2 complexes are basolateral, where they are important for efficient iodide uptake by NIS [140]. Initial studies in MDCK cells seemed to show a lack of influence of overexpressed KCNE subunits on KCNQ1 localization [234]. However, later examination of the MDCK system indicated that while KCNQ1 is programmed to be enriched at the basolateral membrane in this kidney cell line, KCNE1 can reroute KCNQ1 to the apical compartment if crucial KCNQ1 targeting residues are mutated. This supports the possibility of flexibility in KCNQ1 targeting in a given cell type and indicates the potential influence of KCNE subunits even in MDCK cells [235].

The emerging picture is that the polarity of KCNQ1 targeting is both cell type and KCNE-dependent; thus, the influence of the same KCNE isoform differs between cell types. Following the original MDCK study of KCNE-KCNQ1 targeting [234], we examined the influence of Kcne2 and Kcne3 on Kcnq1 localization in parietal cells using singleand double-knockout mice [141]. We found that in $\mathrm{Kcne}^{-/-}$ mice Kcnq1 targets abnormally to the basolateral compartment. We initially thought that this explained the severity of the Kcne2 null mouse phenotype, which surprisingly involves a complete loss of gastric acid secretion despite the continued presence of the pore-forming subunit, Kcnq1. However, upon observing Kcne3 transcript and protein upregulation in Kcne2 null mouse parietal cells, we created double-knockout Kcne $2^{-/-} \mathrm{Kcne}^{-/-}$mice and discovered a surprising phenotype. First, apical expression of Kcnq1 was restored. Yet, despite this, their gastric phenotype was worse than that of single-knockout $\mathrm{Kcne}^{-/-}$mice, with greater gastric hypertrophy. In addition, Kcne3 deletion worsened the hypochlorhydria we observed in heterozygous $\mathrm{Kcne}^{+/-}$mice [141]. We came to the following conclusions: first, KCNE2 is not required for $\mathrm{KCNQ} 1$ apical localization in normal parietal cells but in the absence of KCNE2; abnormally upregulated KCNE3 can hijack KCNQ1 to the basolateral side (Figure 7). Second, homomeric KCNQ1 cannot function sufficiently well to support gastric acid secretion even if apically located; this is probably because KCNE2 is required to be constitutively active and also (perhaps even more important) to be further activated, rather than inhibited, by extracellular protons. Third, although in either case there was minimal parietal cell functionality, it was less damaging for the parietal cells to express basolateral KCNQ1-KCNE3 channels, than apical homomeric KCNQ1 channels [141]. While we do not know the precise explanation for this, it may be that basolateral KCNQ1-KCNE3 channels facilitated exit of some $\mathrm{K}^{+}$(albeit basolaterally) (Figure 7) and therefore delayed the detrimental stagnation of the $\mathrm{K}^{+}$circuit required for $\mathrm{H}^{+} / \mathrm{K}^{+}$ATPase function, whereas apical homomeric KCNQ1 channels were completely nonfunctional [141].

In the choroid plexus epithelium, Kcne2 deletion also resulted in switching of KCNQ1 from the apical to the basolateral membrane (and of Kv1.3, another $\mathrm{Kv} \alpha$ subunit partner of KCNE2 in the choroid plexus) [150]. The contrasting localization and roles of KCNQ1-KCNE2 channels in polarized epithelia are summarized in Figure 5. However, Kcne3 deletion did not result in altered KCNQ1 localization, at least at the level of apical versus basolateral compartmentalization, in the colonic crypts of $\mathrm{Kcne}^{-/-}$mice, in which Kcnq1 was still basolaterally located [166].

Work from the Felipe lab may shed some light on potential KCNE- and cell type-dependence of KCNQ1 trafficking. Using heterologous expression studies in HEK-293 cells they found that when expressed alone, KCNQ1 and KCNE3 were each enriched in caveolin-rich membrane fractions, indicating targeting to sphingolipid-cholesterol-enriched (lipid raft) microdomains. In contrast, the other KCNE subunits did not fractionate with caveolin. Further, they observed that KCNE2 and KCNE5 each efficiently reached the cell surface whereas KCNQ1 and the other KCNEs were less efficiently trafficked to the plasma membrane. Next, expressing various KCNQ1KCNE combinations, the Felipe group found that KCNQ1KCNE1 and KCNQ1-KCNE2 heteromers were enriched in lipid rafts, in contrast to the other combinations, which were not. These data suggest that KCNQ1 and each of the five KCNEs differentially influence each other's membrane microdomain trafficking in HEK cells, creating a number of potential outcomes depending on subunit combination [236].

Finally, many of the KCNQ1 trafficking elements described above were found, in an elegant study, to conspire in the mechanism of estrogen-regulated KCNQ1-KCNE3 trafficking in the colonic epithelium. Building on the prior 

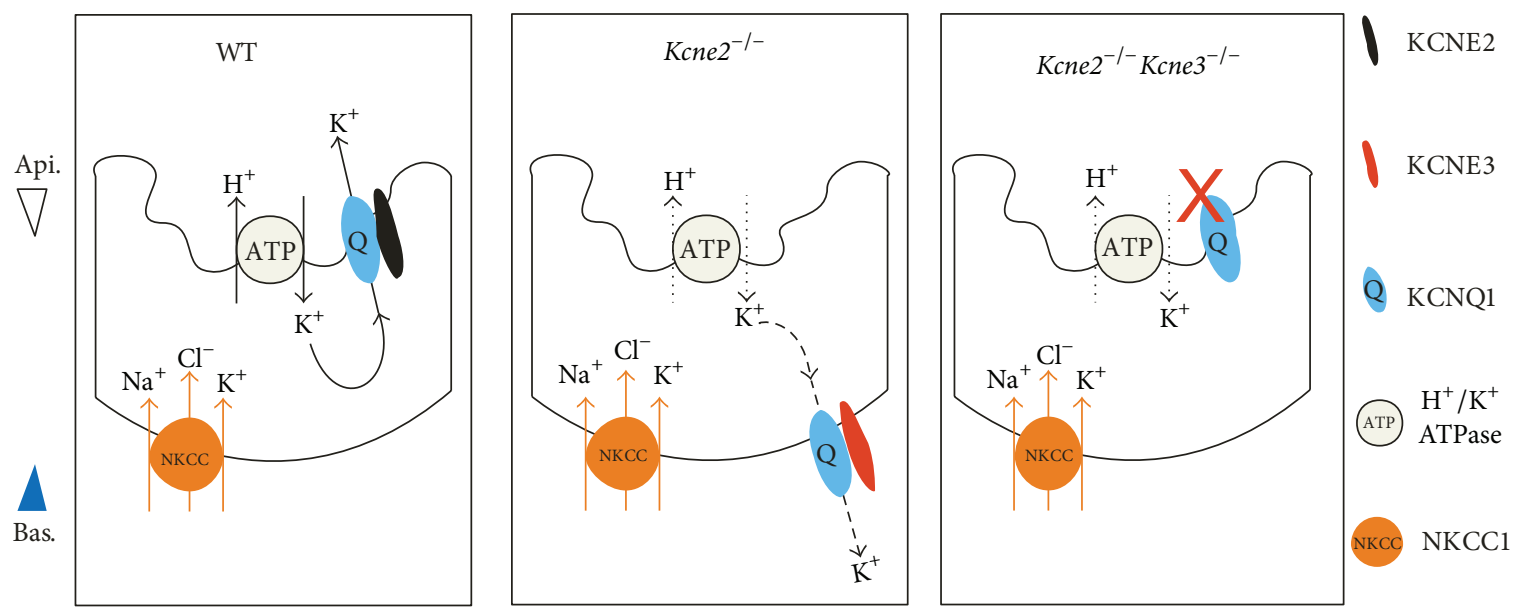

Figure 7: Model of effects of Kcne2/Kcne3 knockout in mouse parietal cells. Model (from [141]) showing the putative short-circuit $\mathrm{K}^{+}$current in parietal cells of $\mathrm{Kcne}^{-/-}$mice (b) compared to $\mathrm{Kcne}^{+/+}$mice (a). This is hypothesized to arise from the previously observed switch in KCNQ1 trafficking from apical $\left(\mathrm{Kcne}^{+/+}\right.$, (a)) to basolateral because of KCNE3 upregulation (b) [141]. In double-knockout $\mathrm{Kcne}^{-/-} \mathrm{Kcne}^{-/-}$ mice, KCNQ1 is apical but presumed nonfunctional because it lacks KCNE2 and KCNE3, which confer constitutive activation and limit inactivation (c) [141].
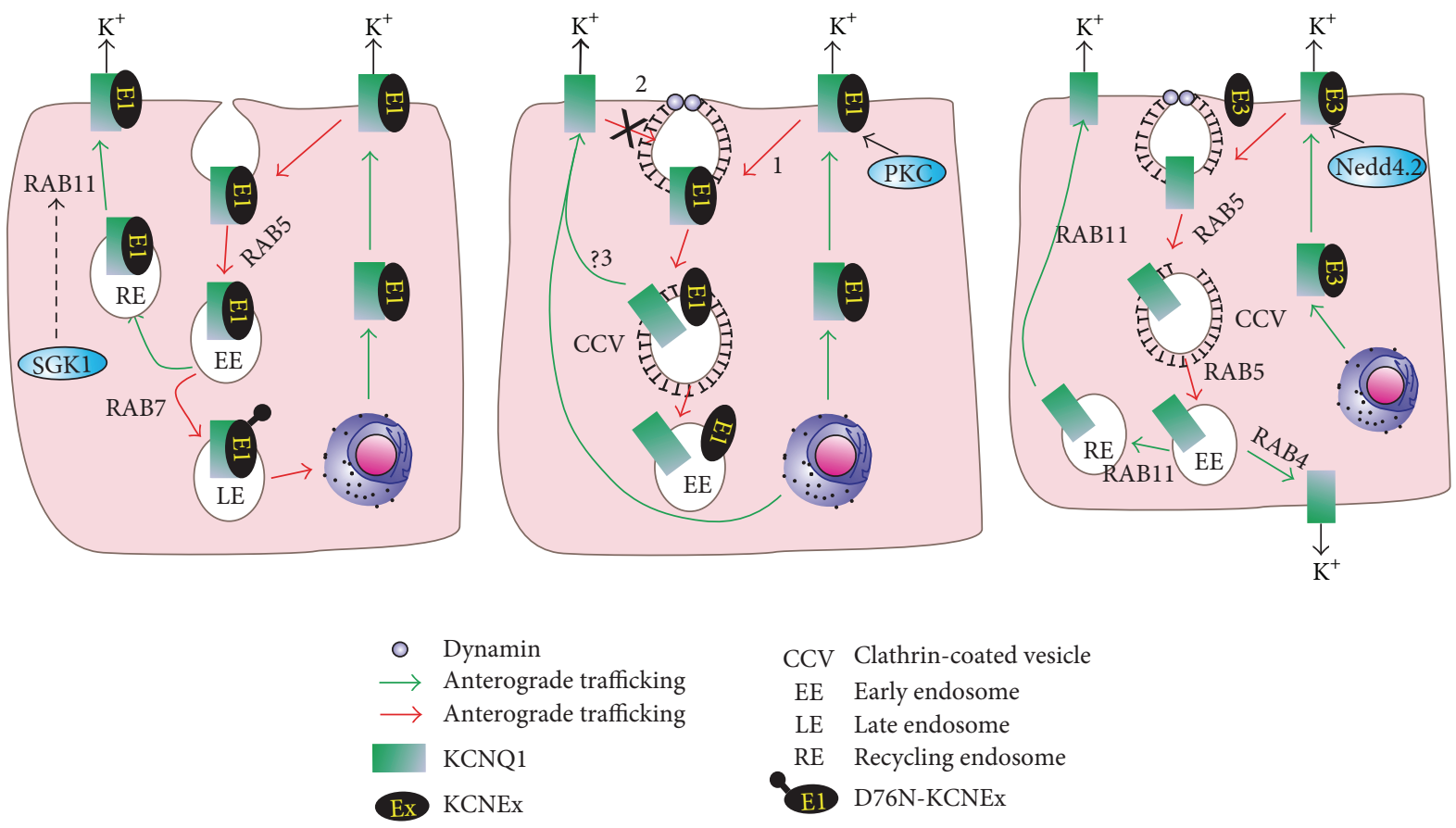

FIGURE 8: Mechanisms of KCNQ1 internalization and recycling. (a) In cardiac myocytes, KCNQ1-KCNE1 complexes can be internalized and recycled by Rab-dependent pathways, with SGK1 stimulating RAB11-dependent recycling in response to stress. $I_{\mathrm{Ks}}$ channels formed with loss-of-function LQTS mutant D76N-KCNE1 are degraded via a RAB7-dependent pathway $[144,145]$. (b) Also in cardiac myocytes, PKC can stimulate KCNE1-dependent clathrin-mediated endocytosis of KCNQ1-KCNE1 (1), whereas homomeric KCNQ1 is not internalized by this pathway (2). This process could favor accumulation of non-KCNE1 channels containing KCNQ1 (3), perhaps in complexes with other KCNE subunits [146, 147]. (c) In the colon, Nedd4.2 (in response to estrogen) stimulates KCNQ1 internalization, leaving KCNE3 at the cell surface. KCNQ1 can be recycled by rapid (Rab4-dependent) or slow (Rabl1-dependent) pathways [148].

discovery that estrogen uncoupled KCNE3 from KCNQ1, the Harvey group found that estrogen stimulated clathrinmediated endocytosis of KCNQ1 in cultured HT29cl.19A colonic cells, by a mechanism that involved direct interaction with the AP-2 adaptor protein. Instead of being degraded after this internalization, KCNQ1 was recycled from early endosomes back to the membrane by a process involving both RAB4 and RAB11. The process also required PKC $\delta$ and AMP-dependent kinase activated by phosphorylation in an estrogen-dependent signaling cascade. Also in this study, 
Nedd4.2 was found to promote KCNQ1 internalization in HT29cl.19A colonic cells, again in response to estrogen [148]. Likewise, AMP-dependent kinase was found to increase KCNQ1 internalization and subsequent degradation in lysosomes, in MDCK cells and in Xenopus oocytes, by activating Nedd4-2. In MDCK cells this process occurred during the early stages of cell polarization $[237,238]$. Mechanisms of KCNQ1 internalization and recycling are summarized in Figure 8.

\section{Conclusion}

The functional diversity and complexity of native ionic currents can be put into perspective when one considers that KCNQ1 is just one of forty $\mathrm{Kv} \alpha$ subunits in the human genome and that $\mathrm{Kv}$ channels represent just one class of S4 containing $\alpha$ subunits, a superfamily that constitutes just one among tens of different ion channel gene families. KCNQ1 can generate a number of different types of $\mathrm{K}^{+}$current made possible largely by the family of KCNE ancillary subunits, which themselves can each regulate multiple other $\mathrm{Kv} \alpha$ subunits. In this by-no-means exhaustive review, the author has attempted to use the example of KCNQ1 to illustrate how ion channels integrate multiple signaling modalities and act as hubs for crosstalk between processes on a wide range of timescales for a variety of physiological ends. KCNQ1 is a uniquely adaptable and versatile ion channel and is therefore essential for a particularly broad range of cellular processes and biological functions, ranging from electrical signaling in cardiac myocytes to maintain the heart beat under stress, control of hormone biosynthesis, gastric acid secretion, and ion, glucose, and cell volume homeostasis.

\section{Conflict of Interests}

The author declares that there is no conflict of interests regarding the publication of this paper.

\section{Acknowledgment}

The author is grateful for financial support from the US National Institutes of Health, HL079275.

\section{References}

[1] B. Hille, C. M. Armstrong, and R. MacKinnon, "Ion channels: from idea to reality," Nature Medicine, vol. 5, no. 10, pp. 11051109, 1999.

[2] W. A. Catterall, "The molecular basis of neuronal excitability," Science, vol. 223, no. 4637, pp. 653-661, 1984.

[3] R. MacKinnon, "Potassium channels," FEBS Letters, vol. 555, no. 1, pp. 62-65, 2003.

[4] M. C. Sanguinetti and A. Zou, "Molecular physiology of cardiac delayed rectifier K+ channels," Heart and Vessels, vol. 12, no. 12, pp. 170-172, 1997.

[5] A. L. Hodgkin and A. F. Huxley, "A quantitative description of membrane current and its application to conduction and excitation in nerve," The Journal of Physiology, vol. 117, no. 4, pp. 500-544, 1952.
[6] A. L. Hodgkin and A. F. Huxley, "The dual effect of membrane potential on sodium conductance in the giant axon of Loligo," The Journal of Physiology, vol. 116, no. 4, pp. 497-506, 1952.

[7] A. L. Hodgkin and A. F. Huxley, "The components of membrane conductance in the giant axon of Loligo," The Journal of Physiology, vol. 116, no. 4, pp. 473-496, 1952.

[8] W. A. Catterall, "Structure and function of voltage-gated ion channels," Annual Review of Biochemistry, vol. 64, pp. 493-531, 1995.

[9] F. Bezanilla and E. Perozo, "The voltage sensor and the gate in ion channels," Advances in Protein Chemistry, vol. 63, pp. 211241, 2003.

[10] L. G. Cuello, D. M. Cortes, and E. Perozo, "Molecular architecture of the KvAP voltage-dependent $\mathrm{K}+$ channel in a lipid bilayer," Science, vol. 306, no. 5695, pp. 491-495, 2004.

[11] P. G. DeCaen, V. Yarov-Yarovoy, E. M. Sharp, T. Scheuer, and W. A. Catterall, "Sequential formation of ion pairs during activation of a sodium channel voltage sensor," Proceedings of the National Academy of Sciences of the United States of America, vol. 106, no. 52, pp. 22498-22503, 2009.

[12] S. B. Long, E. B. Campbell, and R. MacKinnon, "Voltage sensor of Kv1.2: structural basis of electromechanical coupling," Science, vol. 309, no. 5736, pp. 903-908, 2005.

[13] M. Noda, T. Ikeda, H. Suzuki et al., "Expression of functional sodium channels from cloned cDNA," Nature, vol. 322, no. 6082, pp. 826-828, 1986.

[14] S. Numa and M. Noda, "Molecular structure of sodium channels," Annals of the New York Academy of Sciences, vol. 479, pp. 338-355, 1986.

[15] D. M. Papazian, T. L. Schwarz, and B. L. Tempel, "Cloning of genomic and complementary DNA from Shaker, a putative potassium channel gene from Drosophila," Science, vol. 237, no. 4816, pp. 749-753, 1987.

[16] B. L. Tempel, D. M. Papazian, T. L. Schwarz, Y. N. Jan, and L. Y. Jan, "Sequence of probable potassium channel component encoded at Shaker locus of Drosophila," Science, vol. 237, no. 4816, pp. 770-775, 1987.

[17] R. MacKinnon, "Determination of the subunit stoichiometry of a voltage-activated potassium channel," Nature, vol. 350, no. 6315, pp. 232-235, 1991.

[18] D. A. Doyle, J. M. Cabral, R. A. Pfuetzner et al., "The structure of the potassium channel: molecular basis of $\mathrm{K}+$ conduction and selectivity," Science, vol. 280, no. 5360, pp. 69-77, 1998.

[19] S. B. Long, E. B. Campbell, and R. MacKinnon, "Crystal structure of a mammalian voltage-dependent Shaker family K + channel," Science, vol. 309, no. 5736, pp. 897-903, 2005.

[20] Z. A. McCrossan and G. W. Abbott, "The MinK-related peptides," Neuropharmacology, vol. 47, no. 6, pp. 787-821, 2004.

[21] G. Panaghie and G. W. Abbott, "The impact of ancillary subunits on small-molecule interactions with voltage-gated potassium channels," Current Pharmaceutical Design, vol. 12, no. 18, pp. 2285-2302, 2006.

[22] O. Pongs and J. R. Schwarz, "Ancillary subunits associated with voltage-dependent K+ channels," Physiological Reviews, vol. 90, no. 2, pp. 755-796, 2010.

[23] R. Ranganathan, J. H. Lewis, and R. MacKinnon, "Spatial localization of the $\mathrm{K}+$ channel selectivity filter by mutant cyclebased structure analysis," Neuron, vol. 16, no. 1, pp. 131-139, 1996.

[24] Y. Zhou and R. MacKinnon, "The occupancy of ions in the K+ selectivity filter: charge balance and coupling of ion binding to a protein conformational change underlie high conduction rates," Journal of Molecular Biology, vol. 333, no. 5, pp. 965-975, 2003. 
[25] A. L. Hodgkin and A. F. Huxley, "Propagation of electrical signals along giant nerve fibers," Proceedings of the Royal Society of London B, vol. 140, no. 899, pp. 177-183, 1952.

[26] A. L. Hodgkin, A. F. Huxley, and B. Katz, "Measurement of current-voltage relations in the membrane of the giant axon of Loligo," The Journal of Physiology, vol. 116, no. 4, pp. 424-448, 1952.

[27] A. L. Hodgkin and A. F. Huxley, "Movement of sodium and potassium ions during nervous activity," Cold Spring Harbor Symposia on Quantitative Biology, vol. 17, pp. 43-52, 1952.

[28] A. L. Hodgkin and A. F. Huxley, "Movement of radioactive potassium and membrane current in a giant axon," The Journal of Physiology, vol. 121, no. 2, pp. 403-414, 1953.

[29] T. Hoshi and R. W. Aldrich, "Voltage-dependent K+ currents and underlying single $\mathrm{K}+$ channels in pheochromocytoma cells," Journal of General Physiology, vol. 91, no. 1, pp. 73-106, 1988.

[30] T. Hoshi and R. W. Aldrich, "Gating kinetics of the four classes of voltage-dependent $\mathrm{K}+$ channels in pheochromocytoma cells," Journal of General Physiology, vol. 91, no. 1, pp. 107-131, 1988.

[31] M. De Biasi, H. A. Hartmann, J. A. Drewe, M. Taglialatela, A. M. Brown, and G. E. Kirsch, "Inactivation determined by a single site in K+ pores," Pflügers Archiv, vol. 422, no. 4, pp. 354-363, 1993.

[32] Y. M. Cheng, J. Azer, C. M. Niven et al., "Molecular determinants of U-type inactivation in Kv2.1 channels," Biophysical Journal, vol. 101, no. 3, pp. 651-661, 2011.

[33] K. G. Klemic, G. E. Kirsch, and S. W. Jones, "U-type inactivation of Kv3.1 and Shaker potassium channels," Biophysical Journal, vol. 81, no. 2, pp. 814-826, 2001.

[34] T. Hoshi, W. N. Zagotta, and R. W. Aldrich, "Two types of inactivation in Shaker K+ channels: effects of alterations in the carboxy-terminal region," Neuron, vol. 7, no. 4, pp. 547-556, 1991.

[35] M. Holmgren, M. E. Jurman, and G. Yellen, "N-type inactivation and the S4-S5 region of the Shaker K+ channel," Journal of General Physiology, vol. 108, no. 3, pp. 195-206, 1996.

[36] E. Glowatzki, G. Fakler, U. Brandle et al., "Subunit-dependent assembly of inward-rectifier $\mathrm{K}+$ channels," Proceedings of the Royal Society B, vol. 261, no. 1361, pp. 251-261, 1995.

[37] B. Fakler, U. Brandle, E. Glowatzki, H.-P. Zenner, and J. P. Ruppersberg, "K(ir)2.1 inward rectifier $\mathrm{K}+$ channels are regulated independently by protein kinases and ATP hydrolysis," Neuron, vol. 13, no. 6, pp. 1413-1420, 1994.

[38] H. Matsuda, A. Saigusa, and H. Irisawa, "Ohmic conductance through the inwardly rectifying $\mathrm{K}$ channel and blocking by internal Mg2+," Nature, vol. 325, no. 6100, pp. 156-159, 1987.

[39] C. A. Vandenberg, "Inward rectification of a potassium channel in cardiac ventricular cells depends on internal magnesium ions," Proceedings of the National Academy of Sciences of the United States of America, vol. 84, no. 8, pp. 2560-2564, 1987.

[40] B. Fakler, U. Brändle, E. Glowatzki, S. Weidemann, H.-P. Zenner, and J. P. Ruppersberg, "Strong voltage-dependent inward rectification of inward rectifier $\mathrm{K}+$ channels is caused by intracellular spermine," Cell, vol. 80, no. 1, pp. 149-154, 1995.

[41] A. Kollewe, A. Y. Lau, A. Sullivan, B. Roux, and S. A. N. Goldstein, "A structural model for K2P potassium channels based on 23 pairs of interacting sites and continuum electrostatics," Journal of General Physiology, vol. 134, no. 1, pp. 53-68, 2009.

[42] C. M. B. Lopes, N. Zilberberg, and S. A. N. Goldstein, "Block of Kcnk 3 by protons: evidence that 2 -P-domain potassium channel subunits function as homodimers," The Journal of Biological Chemistry, vol. 276, no. 27, pp. 24449-24452, 2001.

[43] S. A. N. Goldstein, L. A. Price, D. N. Rosenthal, and M. H. Pausch, "ORK1, a potassium-selective leak channel with two pore domains cloned from Drosophila melanogaster by expression in Saccharomyces cerevisiae," Proceedings of the National Academy of Sciences of the United States of America, vol. 93, no. 23, pp. 13256-13261, 1996.

[44] K. A. Ketchum, W. J. Joiner, A. J. Sellers, L. K. Kaczmarek, and S. A. N. Goldstein, "A new family of outwardly rectifying potassium channel proteins with two pore domains in tandem," Nature, vol. 376, no. 6542, pp. 690-695, 1995.

[45] S. A. N. Goldstein, K.-W. Wang, N. Ilan, and M. H. Pausch, "Sequence and function of the two $\mathrm{P}$ domain potassium channels: implications of an emerging superfamily," Journal of Molecular Medicine, vol. 76, no. 1, pp. 13-20, 1998.

[46] S. Haider, J. F. Antcliff, P. Proks, M. S. P. Sansom, and F. M. Ashcroft, "Focus on Kir6.2: a key component of the ATPsensitive potassium channel," Journal of Molecular and Cellular Cardiology, vol. 38, no. 6, pp. 927-936, 2005.

[47] J. Barhanin, F. Lesage, E. Guillemare, M. Fink, M. Lazdunski, and G. Romey, "K(V)LQT1 and IsK (minK) proteins associate to form the I(Ks) cardiac potassium current," Nature, vol. 384, no. 6604, pp. 78-80, 1996.

[48] M. C. Sanguinetti, M. E. Curran, A. Zou et al., "Coassembly of K(V)LQT1 and minK (IsK) proteins to form cardiac I(Ks) potassium channel," Nature, vol. 384, no. 6604, pp. 80-83, 1996.

[49] B. C. Schroeder, S. Waldegger, S. Fehr et al., "A constitutively open potassium channel formed by KCNQ1 and KCNE3," Nature, vol. 403, no. 6766, pp. 196-199, 2000.

[50] N. Tinel, S. Diochot, M. Borsotto, M. Lazdunski, and J. Barhanin, "KCNE2 confers background current characteristics to the cardiac KCNQ1 potassium channel," EMBO Journal, vol. 19, no. 23, pp. 6326-6330, 2000.

[51] G. W. Abbott, S. A. N. Goldstein, and F. Sesti, "Do all voltagegated potassium channels use MiRPs?" Circulation Research, vol. 88, no. 10, pp. 981-983, 2001.

[52] T. Takumi, K. Moriyoshi, I. Aramori et al., "Alteration of channel activities and gating by mutations of slow I(SK) potassium channel," The Journal of Biological Chemistry, vol. 266, no. 33, pp. 22192-22198, 1991.

[53] T. Takumi, H. Ohkubo, and S. Nakanishi, "Cloning of a membrane protein that induces a slow voltage-gated potassium current," Science, vol. 242, no. 4881, pp. 1042-1045, 1988.

[54] A. E. Busch and F. Lang, "Effects of [Ca2+](i) and temperature on minK channels expressed in Xenopus oocytes," FEBS Letters, vol. 334, no. 2, pp. 221-224, 1993.

[55] Q. Wang, M. E. Curran, I. Splawski et al., "Positional cloning of a novel potassium channel gene: KVLQT1 mutations cause cardiac arrhythmias," Nature Genetics, vol. 12, no. 1, pp. 17-23, 1996.

[56] E. M. Blumenthal and L. K. Kaczmarek, "The minK potassium channel exists in functional and nonfunctional forms when expressed in the plasma membrane of Xenopus oocytes," Journal of Neuroscience, vol. 14, no. 5, pp. 3097-3105, 1994.

[57] K.-W. Wang and S. A. N. Goldstein, "Subunit composition of MinK potassium channels," Neuron, vol. 14, no. 6, pp. 1303-1309, 1995.

[58] I. Splawski, K. W. Timothy, G. Michael Vincent, D. L. Atkinson, and M. T. Keating, "Molecular basis of the long-QT syndrome associated with deafness," The New England Journal of Medicine, vol. 336, no. 22, pp. 1562-1567, 1997. 
[59] I. Splawski, M. Tristani-Firouzi, M. H. Lehmann, M. C. Sanguinetti, and M. T. Keating, "Mutations in the hminK gene cause long QT syndrome and suppress I(Ks) function," Nature Genetics, vol. 17, no. 3, pp. 338-340, 1997.

[60] L. Bianchi, S. G. Priori, Z. Shen et al., "Cellular dysfunction of LQT5-minK mutants: abnormalities of IKs, IKr and trafficking in long QT syndrome," Human Molecular Genetics, vol. 8, pp. 1499-1507, 1999.

[61] Z. A. McCrossan, T. K. Roepke, A. Lewis, G. Panaghie, and G. W. Abbott, "Regulation of the Kv2.1 potassium channel by MinK and MiRP1," Journal of Membrane Biology, vol. 228, no. 1, pp. 114, 2009.

[62] T. V. McDonald, Z. Yu, Z. Ming et al., "A mink-HERG complex regulates the cardiac potassium current/(Kr)," Nature, vol. 388, no. 6639, pp. 289-292, 1997.

[63] W. M. Jackman, K. J. Friday, J. L. Anderson, E. M. Aliot, M. Clark, and R. Lazzara, "The long QT syndromes: a critical review, new clinical observations and a unifying hypothesis," Progress in Cardiovascular Diseases, vol. 31, no. 2, pp. 115-172, 1988.

[64] W. M. Jackman, M. Clark, and K. J. Friday, "Ventricular tachyarrhythmias in the long QT syndromes," Medical Clinics of North America, vol. 68, no. 5, pp. 1079-1109, 1984.

[65] J. Silva and Y. Rudy, "Subunit interaction determines IKs participation in cardiac repolarization and repolarization reserve," Circulation, vol. 112, no. 10, pp. 1384-1391, 2005.

[66] M. C. Sanguinetti, C. Jiang, M. E. Curran, and M. T. Keating, "A mechanistic link between an inherited and an acquired cardiac arrhythmia: HERG encodes the IKr potassium channel," Cell, vol. 81, no. 2, pp. 299-307, 1995.

[67] G. W. Abbott, F. Sesti, I. Splawski et al., "MiRP1 forms IKr potassium channels with HERG and is associated with cardiac arrhythmia," Cell, vol. 97, no. 2, pp. 175-187, 1999.

[68] M. Zhang, Y. Wang, M. Jiang et al., "KCNE2 protein is more abundant in ventricles than in atria and can accelerate hERG protein degradation in a phosphorylation-dependent manner," American Journal of Physiology: Heart and Circulatory Physiology, vol. 302, no. 4, pp. H910-H922, 2012.

[69] J. R. Ehrlich, M. Pourrier, M. Weerapura et al., "KvLQT1 modulates the distribution and biophysical properties of HERG: a novel $\alpha$-subunit interaction between delayed rectifier currents," The Journal of Biological Chemistry, vol. 279, no. 2, pp. 1233-1241, 2004.

[70] M. Brunner, X. Peng, X. L. Gong et al., "Mechanisms of cardiac arrhythmias and sudden death in transgenic rabbits with long QT syndrome," Journal of Clinical Investigation, vol. 118, no. 6, pp. 2246-2259, 2008.

[71] X.-Q. Ren, G. X. Liu, L. E. Organ-Darling et al., "Pore mutants of HERG and KvLQT1 downregulate the reciprocal currents in stable cell lines," American Journal of Physiology: Heart and Circulatory Physiology, vol. 299, no. 5, pp. H1525-H1534, 2010.

[72] D. J. Tester, M. L. Will, C. M. Haglund, and M. J. Ackerman, "Compendium of cardiac channel mutations in 541 consecutive unrelated patients referred for long QT syndrome genetic testing," Heart Rhythm, vol. 2, no. 5, pp. 507-517, 2005.

[73] G. W. Abbott, "KCNE genetics and pharmacogenomics in cardiac arrhythmias: much ado about nothing?" Expert Review of Clinical Pharmacology, vol. 6, pp. 49-60, 2013.

[74] C. Bellocq, A. C. G. van Ginneken, C. R. Bezzina et al., "Mutation in the KCNQ1 gene leading to the short QT-interval syndrome," Circulation, vol. 109, no. 20, pp. 2394-2397, 2004.
[75] Y.-H. Chen, S.-J. Xu, S. Bendahhou et al., "KCNQ1 gain-offunction mutation in familial atrial fibrillation," Science, vol. 299, no. 5604, pp. 251-254, 2003.

[76] A. Lundby, L. S. Ravn, J. H. Svendsen, S. Hauns, S.-P. Olesen, and N. Schmitt, "KCNE3 mutation V17M identified in a patient with lone atrial fibrillation," Cellular Physiology and Biochemistry, vol. 21, no. 1-3, pp. 47-54, 2008.

[77] K.-J. Ma, N. Li, S.-Y. Teng et al., "Modulation of KCNQ1 current by atrial fibrillation-associated KCNE4 (145E/D) gene polymorphism," Chinese Medical Journal, vol. 120, no. 2, pp. 150-154, 2007.

[78] L. S. Ravn, Y. Aizawa, G. D. Pollevick et al., "Gain of function in IKs secondary to a mutation in KCNE5 associated with atrial fibrillation," Heart Rhythm, vol. 5, no. 3, pp. 427-435, 2008.

[79] L. S. Ravn, J. Hofman-Bang, U. Dixen et al., "Relation of 97T polymorphism in KCNE5 to risk of atrial fibrillation," American Journal of Cardiology, vol. 96, no. 3, pp. 405-407, 2005.

[80] Y. Yang, M. Xia, Q. Jin et al., "Identification of a KCNE2 gainof-function mutation in patients with familial atrial fibrillation," American Journal of Human Genetics, vol. 75, no. 5, pp. 899-905, 2004.

[81] Z. Zeng, C. Tan, S. Teng et al., "The single nucleotide polymorphisms of IKs potassium channel genes and their association with atrial fibrillation in a Chinese population," Cardiology, vol. 108, no. 2, pp. 97-103, 2007.

[82] D.-F. Zhang, B. Liang, J. Lin, B. Liu, Q.-S. Zhou, and Y.-Q. Yang, "KCNE3 R53H substitution in familial atrial fibrillation," Chinese Medical Journal, vol. 118, no. 20, pp. 1735-1738, 2005.

[83] B. C. Knollmann, M. C. Casimiro, A. N. Katchman et al., "Isoproterenol exacerbates a long QT phenotype in Kcnq1deficient neonatal mice: possible roles for human-like Kcnq1 isoform 1 and slow delayed rectifier K+ current," Journal of Pharmacology and Experimental Therapeutics, vol. 310, no. 1, pp. 311-318, 2004.

[84] M. P. Lee, J. D. Ravenel, R.-J. Hu et al., “Targeted disruption of the Kvlqt1 gene causes deafness and gastric hyperplasia in mice," Journal of Clinical Investigation, vol. 106, no. 12, pp. 1447-1455, 2000.

[85] A. Rivas and H. W. Francis, "Inner ear abnormalities in a Kcnq1 (Kvlqt1) knockout mouse: a model of Jervell and Lange-Nielsen syndrome," Otology and Neurotology, vol. 26, no. 3, pp. 415-424, 2005.

[86] N. Neyroud, F. Tesson, I. Denjoy et al., "A novel mutation in the potassium channel gene KVLQT1 causes the Jervell and LangeNielsen cardioauditory syndrome," Nature Genetics, vol. 15, no. 2, pp. 186-189, 1997.

[87] F. Sesti and S. A. N. Goldstein, "Single-channel characteristics of wild-type I(Ks) channels and channels formed with two MinK mutants that cause long QT syndrome," Journal of General Physiology, vol. 112, no. 6, pp. 651-663, 1998.

[88] W.-P. Yang, P. C. Levesque, W. A. Little, M. L. Conder, F. Y. Shalaby, and M. A. Blanar, "KvLQT1, a voltage-gated potassium channel responsible for human cardiac arrhythmias," Proceedings of the National Academy of Sciences of the United States of America, vol. 94, no. 8, pp. 4017-4021, 1997.

[89] M. C. Sanguinetti, M. E. Curran, P. S. Spector, and M. T. Keating, "Spectrum of HERG K+-channel dysfunction in an inherited cardiac arrhythmia," Proceedings of the National Academy of Sciences of the United States of America, vol. 93, no. 5, pp. 22082212, 1996. 
[90] K. J. Ruscic, F. Miceli, C. A. Villalba-Galea et al., "IKs channels open slowly because KCNE1 accessory subunits slow the movement of S4 voltage sensors in KCNQ1 pore-forming subunits," Proceedings of the National Academy of Sciences of the United States of America, vol. 110, pp. E559-E566, 2013.

[91] D. Werry, J. Eldstrom, Z. Wang, and D. Fedida, "Singlechannel basis for the slow activation of the repolarizing cardiac potassium current, I(Ks)," Proceedings of the National Academy of Sciences of the United States of America, vol. 110, pp. E996E1005, 2013.

[92] K. Nakajo and Y. Kubo, "KCNE1 and KCNE3 stabilize and/or slow voltage sensing S4 segment of KCNQ1 channel," Journal of General Physiology, vol. 130, no. 3, pp. 269-281, 2007.

[93] J. M. Rocheleau, S. D. Gage, and W. R. Kobertz, "Secondary structure of a KCNE cytoplasmic domain," Journal of General Physiology, vol. 128, no. 6, pp. 721-729, 2006.

[94] J. D. Osteen, R. Barro-Soria, S. Robey et al., "Allosteric gating mechanism underlies the flexible gating of KCNQ1 potassium channels," Proceedings of the National Academy of Sciences of the United States of America, vol. 109, pp. 7103-7108, 2012.

[95] J. D. Osteen, C. Gonzalez, K. J. Sampson et al., "KCNE1 alters the voltage sensor movements necessary to open the KCNQ1 channel gate," Proceedings of the National Academy of Sciences of the United States of America, vol. 107, no. 52, pp. 22710-22715, 2010.

[96] A. Anantharam, A. Lewis, G. Panaghie et al., "RNA interference reveals that endogenous Xenopus MinK-related peptides govern mammalian $\mathrm{K}+$ channel function in oocyte expression studies," The Journal of Biological Chemistry, vol. 278, no. 14, pp. 11739-11745, 2003.

[97] N. Strutz-Seebohm, M. Pusch, S. Wolf et al., "Structural basis of slow activation gating in the cardiac IKs channel complex," Cellular Physiology and Biochemistry, vol. 27, no. 5, pp. 443-452, 2011.

[98] D. Wu, K. Delaloye, M. A. Zaydman, A. Nekouzadeh, Y. Rudy, and J. Cui, "State-dependent electrostatic interactions of S4 arginines with E1 in S2 during Kv7.1 activation," Journal of General Physiology, vol. 135, no. 6, pp. 595-606, 2010.

[99] D. Wu, H. Pan, K. Delaloye, and J. Cui, "KCNE1 remodels the voltage sensor of Kv7.1 to modulate channel function," Biophysical Journal, vol. 99, no. 11, pp. 3599-3608, 2010.

[100] Y. Yang and F. J. Sigworth, "Single-channel properties of I(Ks) potassium channels," Journal of General Physiology, vol. 112, no. 6, pp. 665-678, 1998.

[101] M. Tristani-Firouzi and M. C. Sanguinetti, "Voltage-dependent inactivation of the human $\mathrm{K}+$ channel KvLQT1 is eliminated by association with minimal $\mathrm{K}+$ channel (minK) subunits," The Journal of Physiology, vol. 510, no. 1, pp. 37-45, 1998.

[102] T. Hoshi and C. M. Armstrong, "C-type inactivation of voltagegated $\mathrm{K}+$ channels: pore constriction or dilation?" The Journal of General Physiology, vol. 141, pp. 151-160, 2013.

[103] T. Baukrowitz and G. Yellen, "Modulation of K+ current by frequency and external $[\mathrm{K}+]$ : a tale of two inactivation mechanisms," Neuron, vol. 15, no. 4, pp. 951-960, 1995.

[104] M. Bleich and R. Warth, "The very small-conductance K+ channel K(V)LQT1 and epithelial function,” Pflügers Archiv, vol. 440, no. 2, pp. 202-206, 2000.

[105] M. C. Casimiro, B. C. Knollmann, S. N. Ebert et al., “Targeted disruption of the Kcnq1 gene produces a mouse model of Jervell and Lange-Nielsen Syndrome," Proceedings of the National Academy of Sciences of the United States of America, vol. 98, no. 5, pp. 2526-2531, 2001.
[106] B. Wollnik, B. C. Schroeder, C. Kubisch, H. D. Esperer, P. Wieacker, and T. J. Jentsch, "Pathophysiological mechanisms of dominant and recessive KVLQT1 K+ channel mutations found in inherited cardiac arrhythmias," Human Molecular Genetics, vol. 6, no. 11, pp. 1943-1949, 1997.

[107] E. Schulze-Bahr, Q. Wang, H. Wedekind et al., "KCNE1 mutations cause jervell and Lange-Nielsen syndrome," Nature Genetics, vol. 17, no. 3, pp. 267-268, 1997.

[108] F. F. Offner, P. Dallos, and M. A. Cheatham, "Positive endocochlear potential: mechanism of production by marginal cells of stria vascularis," Hearing Research, vol. 29, no. 2-3, pp. 117-124, 1987.

[109] P. Wangemann, "K+ cycling and the endocochlear potential," Hearing Research, vol. 165, no. 1-2, pp. 1-9, 2002.

[110] S. Demolombe, D. Franco, P. de Boer et al., "Differential expression of KvLQT1 and its regulator IsK in mouse epithelia," American Journal of Physiology: Cell Physiology, vol. 280, no. 2, pp. C359-C372, 2001.

[111] R. Warth, M. Garcia Alzamora, J. Kim et al., "The role of KCNQ1/KCNE1 K+ channels in intestine and pancreas: lessons from the KCNE1 knockout mouse," Pflügers Archiv, vol. 443, no. 5-6, pp. 822-828, 2002.

[112] K. Yamagata, T. Senokuchi, M. Lu et al., "Voltage-gated K+ channel KCNQ1 regulates insulin secretion in MIN6 $\beta$-cell line," Biochemical and Biophysical Research Communications, vol. 407, no. 3, pp. 620-625, 2011.

[113] M. Kuwamura, R. Okajima, J. Yamate, T. Kotani, T. Kuramoto, and T. Serikawa, "Pancreatic metaplasia in the gastroachlorhydria in WTC-dfk rat, a potassium channel Kcnql mutant," Veterinary Pathology, vol. 45, no. 4, pp. 586-591, 2008.

[114] S. Ullrich, J. Su, F. Ranta et al., "Effects of IKs channel inhibitors in insulin-secreting INS-1 cells," Pflügers Archiv, vol. 451, no. 3, pp. 428-436, 2005.

[115] Y.-H. Lee, E. S. Kang, S. H. Kim et al., "Association between polymorphisms in SLC30A8, HHEX, CDKN2A/B, IGF2BP2, FTO, WFS1, CDKAL1, KCNQ1 and type 2 diabetes in the Korean population," Journal of Human Genetics, vol. 53, no. 1112, pp. 991-998, 2008.

[116] Y. Liu, D. Z. Zhou, D. Zhang et al., "Variants in KCNQ1 are associated with susceptibility to type 2 diabetes in the population of mainland China," Diabetologia, vol. 52, no. 7, pp. 1315-1321, 2009.

[117] H. Unoki, A. Takahashi, T. Kawaguchi et al., "SNPs in KCNQ1 are associated with susceptibility to type 2 diabetes in East Asian and European populations," Nature Genetics, vol. 40, no. 9, pp. 1098-1102, 2008.

[118] K. Yasuda, K. Miyake, Y. Horikawa et al., "Variants in KCNQ1 are associated with susceptibility to type 2 diabetes mellitus," Nature Genetics, vol. 40, no. 9, pp. 1092-1097, 2008.

[119] J.-B. Zhou, J.-K. Yang, L. Zhao, and Z. Xin, "Variants in KCNQ1, AP3S1, MAN2A1, and ALDH7A1 and the risk of type 2 diabetes in the Chinese northern Han population: a case-control study and meta-analysis," Medical Science Monitor, vol. 16, no. 6, pp. BR179-BR183, 2010.

[120] Q. Zhou, K. Zhang, W. Li et al., "Association of KCNQ1 gene polymorphism with gestational diabetes mellitus in a Chinese population," Diabetologia, vol. 52, no. 11, pp. 2466-2468, 2009.

[121] K. Müssig, H. Staiger, F. Machicao et al., "Association of type 2 diabetes candidate polymorphisms in KCNQ1 with incretin and insulin secretion," Diabetes, vol. 58, no. 7, pp. 1715-1720, 2009. 
[122] Q. Qi, H. Li, R. J. F. Loos et al., "Common variants in KCNQ1 are associated with type 2 diabetes and impaired fasting glucose in a Chinese Han population," Human Molecular Genetics, vol. 18, no. 18, pp. 3508-3515, 2009.

[123] T. Ohshige, Y. Tanaka, S.-I. Araki et al., "A single nucleotide polymorphism in KCNQ1 is associated with susceptibility to diabetic nephropathy in Japanese subjects with type 2 diabetes," Diabetes Care, vol. 33, no. 4, pp. 842-846, 2010.

[124] W. Yu, C. Hu, R. Zhang et al., "Effects of KCNQ1 polymorphisms on the therapeutic efficacy of oral antidiabetic drugs in Chinese patients with type 2 diabetes," Clinical Pharmacology and Therapeutics, vol. 89, no. 3, pp. 437-442, 2011.

[125] A. H. Rosengren, M. Braun, T. Mahdi et al., "Reduced insulin exocytosis in human pancreatic beta-cells with gene variants linked to type 2 diabetes," Diabetes, vol. 61, pp. 1726-1733, 2012.

[126] K. M. Boini, D. Graf, A. M. Hennige et al., "Enhanced insulin sensitivity of gene-targeted mice lacking functional KCNQ1," American Journal of Physiology: Regulatory Integrative and Comparative Physiology, vol. 296, no. 6, pp. R1695-R1701, 2009.

[127] M. E. Travers, D. J. Mackay, M. Dekker Nitert et al., "Insights into the molecular mechanism for type 2 diabetes susceptibility at the KCNQ1 locus from temporal changes in imprinting status in human islets," Diabetes, vol. 62, pp. 987-992, 2013.

[128] V. Vallon, F. Grahammer, K. Richter et al., "Role of KCNE1dependent $\mathrm{K}+$ fluxes in mouse proximal tubule," Journal of the American Society of Nephrology, vol. 12, no. 10, pp. 2003-2011, 2001.

[129] R. B. Puchalski, E. Kelly, A. A. Bachmanov et al., "NaCl consumption is attenuated in female KCNE1 null mutant mice," Physiology and Behavior, vol. 74, no. 3, pp. 267-276, 2001.

[130] H. Barrière, I. Rubera, R. Belfodil et al., "Swelling-activated chloride and potassium conductance in primary cultures of mouse proximal tubules. Implication of KCNE1 protein," Journal of Membrane Biology, vol. 193, no. 3, pp. 153-170, 2003.

[131] I. D. Millar, J. A. Hartley, C. Haigh et al., "Volume regulation is defective in renal proximal tubule cells isolated from KCNE1 knockout mice," Experimental Physiology, vol. 89, no. 2, pp. 173180, 2004.

[132] A. M. Neal, H. C. Taylor, I. D. Millar, J. D. Kibble, S. J. White, and L. Robson, "Renal defects in KCNE1 knockout mice are mimicked by chromanol 293B in vivo: identification of a KCNE1-regulated $\mathrm{K}+$ conductance in the proximal tubule," The Journal of Physiology, vol. 589, no. 14, pp. 3595-3609, 2011.

[133] V. Vallon, F. Grahammer, H. Volkl et al., "KCNQ1-dependent transport in renal and gastrointestinal epithelia," Proceedings of the National Academy of Sciences of the United States of America, vol. 102, no. 49, pp. 17864-17869, 2005.

[134] A. M. Goldman, E. Glasscock, J. Yoo, T. T. Chen, T. L. Klassen, and J. L. Noebels, "Arrhythmia in heart and brain: KCNQ1 mutations link epilepsy and sudden unexplained death," Science Translational Medicine, vol. 1, no. 2, p. 2ra6, 2009.

[135] F. Grahammer, A. W. Herling, H. J. Lang et al., "The cardiac $\mathrm{K}+$ channel KCNQ1 is essential for gastric acid secretion," Gastroenterology, vol. 120, no. 6, pp. 1363-1371, 2001.

[136] T. K. Roepke, A. Anantharam, P. Kirchhoff et al., “The KCNE2 potassium channel ancillary subunit is essential for gastric acid secretion," The Journal of Biological Chemistry, vol. 281, no. 33, pp. 23740-23747, 2006.

[137] D. Heitzmann, F. Grahammer, T. von Hahn et al., "Heteromeric KCNE2/KCNQ1 potassium channels in the luminal membrane of gastric parietal cells," The Journal of Physiology, vol. 561, no. 2, pp. 547-557, 2004.
[138] D. Heitzmann, V. Koren, M. Wagner et al., "KCNE beta subunits determine $\mathrm{pH}$ sensitivity of KCNQ1 potassium channels," Cellular Physiology and Biochemistry, vol. 19, no. 1-4, pp. 21-32, 2007.

[139] T. K. Roepke, K. Purtell, E. C. King, K. M. D. la Perle, D. J. Lerner, and G. W. Abbott, "Targeted deletion of Kcne2 causes gastritis cystica profunda and gastric neoplasia," PLOS ONE, vol. 5, no. 7, Article ID e11451, 2010.

[140] T. K. Roepke, E. C. King, A. Reyna-Neyra et al., "Kone2 deletion uncovers its crucial role in thyroid hormone biosynthesis," Nature Medicine, vol. 15, no. 10, pp. 1186-1194, 2009.

[141] T. K. Roepke, E. C. King, K. Purtell, V. A. Kanda, D. J. Lerner, and G. W. Abbott, "Genetic dissection reveals unexpected influence of $\beta$ subunits on KCNQ1 $\mathrm{K}+$ channel polarized trafficking in vivo," FASEB Journal, vol. 25, no. 2, pp. 727-736, 2011.

[142] C. Riedel, O. Dohán, A. de la Vieja, C. S. Ginter, and N. Carrasco, "Journey of the iodide transporter NIS: from its molecular identification to its clinical role in cancer," Trends in Biochemical Sciences, vol. 26, no. 8, pp. 490-496, 2001.

[143] K. Purtell, M. Paroder-Belenitsky, A. Reyna-Neyra et al., “The KCNQ1-KCNE2 $\mathrm{K}+$ channel is required for adequate thyroid Iuptake," FASEB Journal, vol. 26, no. 8, pp. 3252-3259, 2012.

[144] G. Seebohm, N. Strutz-Seebohm, R. Birkin et al., "Regulation of endocytic recycling of KCNQ1/KCNE1 potassium channels," Circulation Research, vol. 100, no. 5, pp. 686-692, 2007.

[145] G. Seebohm, N. Strutz-Seebohm, O. N. Ureche et al., "Long QT syndrome-associated mutations in KCNQ1 and KCNE1 subunits disrupt normal endosomal recycling of IKs channels," Circulation Research, vol. 103, no. 12, pp. 1451-1457, 2008.

[146] X. Xu, V. A. Kanda, E. Choi et al., "MinK-dependent internalization of the IKs potassium channel," Cardiovascular Research, vol. 82, no. 3, pp. 430-438, 2009.

[147] V. A. Kanda, K. Purtell, and G. W. Abbott, "Protein kinase C downregulates IKs by stimulating KCNQ1-KCNE1 potassium channel endocytosis," Heart Rhythm, vol. 8, no. 10, pp. 16411647, 2011.

[148] R. Rapetti-Mauss, F. O’Mahony, F. V. Sepulveda, V. Urbach, and B. J. Harvey, "Oestrogen promotes KCNQ1 potassium channel endocytosis and postendocytic trafficking in colonic epithelium," The Journal of Physiology, vol. 591, pp. 2813-2831, 2013.

[149] H. Fröhlich, K. M. Boini, G. Seebohm et al., "Hypothyroidism of gene-targeted mice lacking Kcnq1," Pflügers Archiv, vol. 461, no. 1, pp. 45-52, 2011.

[150] T. K. Roepke, V. A. Kanda, K. Purtell, E. C. King, D. J. Lerner, and G. W. Abbott, "KCNE2 forms potassium channels with KCNA3 and KCNQ1 in the choroid plexus epithelium," FASEB Journal, vol. 25, no. 12, pp. 4264-4273, 2011.

[151] M. Jiang, X. Xu, Y. Wang et al., "Dynamic partnership between KCNQ1 and KCNE1 and influence on cardiac IKs current amplitude by KCNE2," The Journal of Biological Chemistry, vol. 284, no. 24, pp. 16452-16462, 2009.

[152] F. Toyoda, H. Ueyama, W.-G. Ding, and H. Matsuura, "Modulation of functional properties of KCNQ1 channel by association of KCNE1 and KCNE2," Biochemical and Biophysical Research Communications, vol. 344, no. 3, pp. 814-820, 2006.

[153] D.-M. Wu, M. Jiang, M. Zhang, X.-S. Liu, Y. V. Korolkova, and G.-N. Tseng, "KCNE2 is colocalized with KCNQ1 and KCNE1 in cardiac myocytes and may function as a negative modulator of IKs current amplitude in the heart," Heart Rhythm, vol. 3, no. 12, pp. 1469-1480, 2006. 
[154] H. Yu, J. Wu, I. Potapova et al., "MinK-related peptide 1: a beta subunit for the HCN ion channel subunit family enhances expression and speeds activation," Circulation Research, vol. 88, no. 12, pp. E84-E87, 2001.

[155] J. Yan and R. W. Aldrich, "BK potassium channel modulation by leucine-rich repeat-containing proteins," Proceedings of the National Academy of Sciences of the United States of America, vol. 109, pp. 7917-7922, 2012.

[156] J. Yan and R. W. Aldrich, "LRRC26 auxiliary protein allows BK channel activation at resting voltage without calcium," Nature, vol. 466, no. 7305, pp. 513-516, 2010.

[157] G. W. Abbott, M. H. Butler, S. Bendahhou, M. C. Dalakas, L. J. Ptacek, and S. A. N. Goldstein, "MiRP2 forms potassium channels in skeletal muscle with Kv3.4 and is associated with periodic paralysis," Cell, vol. 104, no. 2, pp. 217-231, 2001.

[158] G. W. Abbott, M. H. Butler, and S. A. N. Goldstein, "Phosphorylation and protonation of neighboring MiRP2 sites: function and pathophysiology of MiRP2-Kv3.4 potassium channels in periodic paralysis," FASEB Journal, vol. 20, no. 2, pp. 293-301, 2006.

[159] G. W. Abbott and S. A. N. Goldstein, "Disease-associated mutations in KCNE potassium channel subunits (MiRPs) reveal promiscuous disruption of multiple currents and conservation of mechanism," FASEB Journal, vol. 16, no. 3, pp. 390-400, 2002.

[160] G. Panaghie and G. W. Abbott, "The role of S4 charges in voltage-dependent and voltage-independent KCNQ1 potassium channel complexes," Journal of General Physiology, vol. 129, no. 2, pp. 121-133, 2007.

[161] E. Choi and G. W. Abbott, "A shared mechanism for lipid- and $\beta$-subunit-coordinated stabilization of the activated $\mathrm{K}+$ channel voltage sensor," FASEB Journal, vol. 24, no. 5, pp. 1518-1524, 2010.

[162] Y. F. Melman, A. Domènech, S. de la Luna, and T. V. McDonald, "Structural determinants of KvLQT1 control by the KCNE family of proteins," The Journal of Biological Chemistry, vol. 276, no. 9, pp. 6439-6444, 2001.

[163] Y. F. Melman, A. Krumerman, and T. V. McDonald, "A single transmembrane site in the KCNE-encoded proteins controls the specificity of KvLQT1 channel gating," The Journal of Biological Chemistry, vol. 277, no. 28, pp. 25187-25194, 2002.

[164] G. Panaghie, K.-K. Tai, and G. W. Abbott, "Interaction of KCNE subunits with the KCNQ1 K+ channel pore," The Journal of Physiology, vol. 570, no. 3, pp. 455-467, 2006.

[165] E. Gordon, T. K. Roepke, and G. W. Abbott, "Endogenous KCNE subunits govern Kv2.1 K+ channel activation kinetics in Xenopus oocyte studies," Biophysical Journal, vol. 90, no. 4, pp. 1223-1231, 2006.

[166] P. Preston, L. Wartosch, D. Günzel et al., "Disruption of the $\mathrm{K}+$ channel $\beta$-subunit KCNE3 reveals an important role in intestinal and tracheal Cl- transport," The Journal of Biological Chemistry, vol. 285, no. 10, pp. 7165-7175, 2010.

[167] A. Boucherot, R. Schreiber, and K. Kunzelmann, "Regulation and properties of KCNQ1 (KvLQT1) and impact of the cystic fibrosis transmembrane conductance regulator," Journal of Membrane Biology, vol. 182, no. 1, pp. 39-47, 2001.

[168] K. Dedek and S. Waldegger, "Colocalization of KCNQ1/KCNE channel subunits in the mouse gastrointestinal tract," Pflügers Archiv, vol. 442, no. 6, pp. 896-902, 2001.

[169] F. O’Mahony, W. Thomas, and B. J. Harvey, "Novel female sexdependent actions of oestrogen in the intestine," The Journal of Physiology, vol. 587, no. 21, pp. 5039-5044, 2009.
[170] R. Alzamora, F. O’Mahony, V. Bustos et al., “Sexual dimorphism and oestrogen regulation of KCNE3 expression modulates the functional properties of KCNQ1 K+ channels," The Journal of Physiology, vol. 589, no. 21, pp. 5091-5107, 2011.

[171] B. L. vanTol, S. Missan, J. Crack et al., "Contribution of KCNQ1 to the regulatory volume decrease in the human mammary epithelial cell line MCF-7," American Journal of Physiology: Cell Physiology, vol. 293, no. 3, pp. C1010-C1019, 2007.

[172] S. Hammami, N. J. Willumsen, H. L. Olsen, F. J. Morera, R. Latorre, and D. A. Klaerke, "Cell volume and membrane stretch independently control K+ channel activity," The Journal of Physiology, vol. 587, no. 10, pp. 2225-2231, 2009.

[173] F. Grahammer, R. Warth, J. Barhanin, M. Bleich, and M. J. Hug, "The Small Conductance K+ Channel, KCNQ1. Expression, function, and subunit composition in murine trachea," The Journal of Biological Chemistry, vol. 276, no. 45, pp. 4226842275, 2001.

[174] J. K. Kim, H. Y. Yoo, S. J. Kim et al., "Effects of sevoflurane on the cAMP-induced short-circuit current in mouse tracheal epithelium and recombinant $\mathrm{Cl}-$ (CFTR) and $\mathrm{K}+$ (KCNQ1) channels," British Journal of Anaesthesia, vol. 99, no. 2, pp. 245251, 2007.

[175] R. Schreiber, B. Mürle, J. Sun, and K. Kunzelmann, “Electrolyte transport in the mouse trachea: no evidence for a contribution of luminal K+ conductance," Journal of Membrane Biology, vol. 189, no. 2, pp. 143-151, 2002.

[176] S. M. Kreda, C. W. Davis, and M. C. Rose, "CFTR, mucins, and mucus obstruction in cystic fibrosis," Cold Spring Harbor Perspectives in Medicine, vol. 2, Article ID a009589, 2012.

[177] M. Soler Artigas, D. W. Loth, L. V. Wain et al., "Genomewide association and large-scale follow up identifies 16 new loci influencing lung function," Nature Genetics, vol. 43, pp. 10821090, 2011.

[178] E. A. Cowley and P. Linsdell, "Characterizatin of basolateral K+ channels underlying anion secretion in the human airway cell line Calu-3," The Journal of Physiology, vol. 538, no. 3, pp. 747757, 2002.

[179] G. W. Abbott and S. A. N. Goldstein, "A superfamily of small potassium channel subunits: form and function of the MinKrelated peptides (MiRPs)," Quarterly Reviews of Biophysics, vol. 31, no. 4, pp. 357-398, 1998.

[180] M. Grunnet, T. Jespersen, H. B. Rasmussen et al., "KCNE4 is an inhibitory subunit to the KCNQ1 channel," The Journal of Physiology, vol. 542, no. 1, pp. 119-130, 2002.

[181] L. J. Manderfield and A. L. George Jr., "KCNE4 can co-associate with the IKs (KCNQ1-KCNE1) channel complex," FEBS Journal, vol. 275, no. 6, pp. 1336-1349, 2008.

[182] S. Teng, L. Ma, Y. Zhen et al., "Novel gene hKCNE4 slows the activation of the KCNQ1 channel," Biochemical and Biophysical Research Communications, vol. 303, no. 3, pp. 808-813, 2003.

[183] M. Grunnet, S.-P. Olesen, D. A. Klaerke, and T. Jespersen, "hKCNE4 inhibits the hKCNQ1 potassium current without affecting the activation kinetics," Biochemical and Biophysical Research Communications, vol. 328, no. 4, pp. 1146-1153, 2005.

[184] S. Bendahhou, C. Marionneau, K. Haurogne et al., "In vitro molecular interactions and distribution of KCNE family with KCNQ1 in the human heart," Cardiovascular Research, vol. 67, no. 3, pp. 529-538, 2005.

[185] L. J. Manderfield, M. A. Daniels, C. G. Vanoye, and A. L. George Jr., "KCNE4 domains required for inhibition of KCNQ1," The Journal of Physiology, vol. 587, no. 2, pp. 303-314, 2009. 
[186] A. J. Labro, I. R. Boulet, F. S. Choveau et al., "The S4-S5 linker of KCNQ1 channels forms a structural scaffold with the S6 segment controlling gate closure," The Journal of Biological Chemistry, vol. 286, no. 1, pp. 717-725, 2011.

[187] A. Lvov, S. D. Gage, V. M. Berrios, and W. R. Kobertz, "Identification of a protein-protein interaction between KCNE1 and the activation gate machinery of KCNQ1," Journal of General Physiology, vol. 135, no. 6, pp. 607-618, 2010.

[188] F. S. Choveau, N. Rodriguez, F. A. Ali et al., "KCNQ1 channels voltage dependence through a voltage-dependent binding of the S4-S5 linker to the pore domain," The Journal of Biological Chemistry, vol. 286, no. 1, pp. 707-716, 2011.

[189] E. J. Ciampa, R. C. Welch, C. G. Vanoye, and A. L. George Jr., "KCNE4 juxtamembrane region is required for interaction with calmodulin and for functional suppression of KCNQ1," The Journal of Biological Chemistry, vol. 286, no. 6, pp. 4141-4149, 2011.

[190] M. Piccini, F. Vitelli, M. Seri et al., "KCNE1-like gene is deleted in ACME contiguous gene syndrome: identification and characterization of the human and mouse homologs," Genomics, vol. 60, no. 3, pp. 251-257, 1999.

[191] K. Angelo, T. Jespersen, M. Grunnet, M. S. Nielsen, D. A. Klaerke, and S.-P. Olesen, "KCNE5 induces time- and voltagedependent modulation of the KCNQ1 current," Biophysical Journal, vol. 83, no. 4, pp. 1997-2006, 2002.

[192] B. R. Palmer, C. M. Frampton, L. Skelton et al., "KCNE5 polymorphism rs697829 is associated with QT interval and survival in acute coronary syndromes patients," Journal of Cardiovascular Electrophysiology, vol. 23, no. 3, pp. 319-324, 2012.

[193] S. Ohno, D. P. Zankov, W.-G. Ding et al., "KCNE5 (KCNE1L) variants are novel modulators of brugada syndrome and idiopathic ventricular fibrillation," Circulation, vol. 4, no. 3, pp. 352361, 2011.

[194] M. P. Lee, M. R. DeBaun, K. Mitsuya et al., "Loss of imprinting of a paternally expressed transcript, with antisense orientation to KVLQT1, occurs frequently in Beckwith-Wiedemann syndrome and is independent of insulin-like growth factor II imprinting," Proceedings of the National Academy of Sciences of the United States of America, vol. 96, no. 9, pp. 5203-5208, 1999.

[195] M. P. Lee, R.-J. Hu, L. A. Johnson, and A. P. Feinberg, "Human KVLQT1 gene shows tissue-specific imprinting and encompasses Beckwith-Wiedemann syndrome chromosomal rearrangements," Nature Genetics, vol. 15, no. 2, pp. 181-185, 1997.

[196] F. Gurrieri, M. Zollino, A. Oliva et al., "Mild BeckwithWiedemann and severe long-QT syndrome due to deletion of the imprinting center 2 on chromosome 11p," European Journal of Human Genetics, vol. 21, pp. 965-969, 2013.

[197] D. Serre, S. Gurd, B. Ge et al., "Differential allelic expression in the human genome: a robust approach to identify genetic and epigenetic Cis-acting mechanisms regulating gene expression," PLoS Genetics, vol. 4, no. 2, Article ID e1000006, 2008.

[198] R. R. Pandey, T. Mondal, F. Mohammad et al., "Kcnqlotl antisense noncoding RNA mediates lineage-specific transcriptional silencing through chromatin-level regulation," Molecular Cell, vol. 32, no. 2, pp. 232-246, 2008.

[199] C. Kanduri, "Kcnqlot1: a chromatin regulatory RNA," Seminars in Cell and Developmental Biology, vol. 22, no. 4, pp. 343-350, 2011.
[200] L. Korostowski, N. Sedlak, and N. Engel, “The Kcnqlotl long non-coding RNA affects chromatin conformation and expression of Kcnql, but does not regulate its imprinting in the developing heart," PLoS Genet, vol. 8, Article ID e1002956, 2012.

[201] A. P. Larsen, A. B. Steffensen, M. Grunnet, and S.-P. Olesen, "Extracellular potassium inhibits Kv7.1 potassium channels by stabilizing an inactivated state," Biophysical Journal, vol. 101, no. 4, pp. 818-827, 2011.

[202] H. Zhang, L. C. Craciun, T. Mirshahi et al., "PIP2 activates KCNQ channels, and its hydrolysis underlies receptor-mediated inhibition of M currents," Neuron, vol. 37, no. 6, pp. 963-975, 2003.

[203] G. Loussouarn, K.-H. Park, C. Bellocq, I. Baró, F. Charpentier, and D. Escande, "Phosphatidylinositol-4,5-bisphosphate, PIP2, controls KCNQ1/KCNE1 voltage-gated potassium channels: a functional homology between voltage-gated and inward rectifier K+ channels," EMBO Journal, vol. 22, no. 20, pp. 5412-5421, 2003.

[204] N. Rodriguez, M. Y. Amarouch, J. Montnach et al., "Phosphatidylinositol-4,5-bisphosphate (PIP2) stabilizes the open pore conformation of the Kv1l.1 (hERG) channel," Biophysical Journal, vol. 99, no. 4, pp. 1110-1118, 2010.

[205] B. Ribalet, S. A. John, and J. N. Weiss, "Regulation of cloned ATP-sensitive $\mathrm{K}$ channels by phosphorylation, MgADP, and phosphatidylinositol bisphosphate (PIP2): a study of channel rundown and reactivation," Journal of General Physiology, vol. 116, no. 3, pp. 391-409, 2000.

[206] K.-H. Park, J. Piron, S. Dahimene et al., "Impaired KCNQ1KCNE1 and phosphatidylinositol-4,5-bisphosphate interaction underlies the long QT syndrome," Circulation Research, vol. 96, no. 7, pp. 730-739, 2005.

[207] J. Piron, F. S. Choveau, M. Y. Amarouch et al., "KCNE1KCNQ1 osmoregulation by interaction of phosphatidylinositol4,5-bisphosphate with $\mathrm{Mg} 2+$ and polyamines," The Journal of Physiology, vol. 588, no. 18, pp. 3471-3483, 2010.

[208] Y. Li, M. A. Zaydman, D. Wu et al., "KCNE1 enhances phosphatidylinositol 4,5-bisphosphate (PIP2) sensitivity of IKs to modulate channel activity," Proceedings of the National Academy of Sciences of the United States of America, vol. 108, no. 22, pp. 9095-9100, 2011.

[209] P. Zhou, H. Yu, M. Gu et al., "Phosphatidylinositol 4, 5bisphosphate alters pharmacological selectivity for epilepsycausing KCNQ potassium channels," Proceedings of the National Academy of Sciences of the United States of America, vol. 110, pp. 8726-8731, 2013.

[210] Y. Zheng, X. Zhu, P. Zhou et al., "Hexachlorophene is a potent KCNQ1/KCNE1 potassium channel activator which rescues LQTs mutants," PLoS ONE, vol. 7, Article ID e51820, 2012.

[211] S. O. Marx, J. Kurokawa, S. Reiken et al., "Requirement of a macromolecular signaling complex for $\beta$ adrenergic receptor modulation of the KCNQ1-KCNE1 potassium channel," Science, vol. 295, no. 5554, pp. 496-499, 2002.

[212] C. Terrenoire, M. D. Houslay, G. S. Baillie, and R. S. Kass, "The cardiac IKs potassium channel macromolecular complex includes the phosphodiesterase PDE4D3," The Journal of Biological Chemistry, vol. 284, no. 14, pp. 9140-9146, 2009.

[213] Y. Li, L. Chen, R. S. Kass, and C. W. Dessauer, "The A-kinase anchoring protein Yotiao facilitates complex formation between adenylyl cyclase type 9 and the IKs potassium channel in heart," The Journal of Biological Chemistry, vol. 287, pp. 29815-29824, 2012. 
[214] L. Chen and R. S. Kass, "Dual roles of the A kinase-anchoring protein Yotiao in the modulation of a cardiac potassium channel: a passive adaptor versus an active regulator," European Journal of Cell Biology, vol. 85, no. 7, pp. 623-626, 2006.

[215] L. Chen, M. L. Marquardt, D. J. Tester, K. J. Sampson, M. J. Ackerman, and R. S. Kass, "Mutation of an A-kinase-anchoring protein causes long-QT syndrome," Proceedings of the National Academy of Sciences of the United States of America, vol. 104, no. 52, pp. 20990-20995, 2007.

[216] J. J. Saucerman, S. N. Healy, M. E. Belik, J. L. Puglisi, and A. D. McCulloch, "Proarrhythmic consequences of a KCNQ1 AKAPbinding domain mutation: computational models of whole cells and heterogeneous tissue," Circulation Research, vol. 95, no. 12, pp. 1216-1224, 2004.

[217] H. Wen and I. B. Levitan, "Calmodulin is an auxiliary subunit of KCNQ2/3 potassium channels," Journal of Neuroscience, vol. 22, no. 18, pp. 7991-8001, 2002.

[218] S. Ghosh, D. A. Nunziato, and G. S. Pitt, "KCNQ1 assembly and function is blocked by long-QT syndrome mutations that disrupt interaction with calmodulin," Circulation Research, vol. 98, no. 8, pp. 1048-1054, 2006.

[219] L. Shamgar, L. Ma, N. Schmitt et al., "Calmodulin is essential for cardiac IKS channel gating and assembly: impaired function in long-QT mutations," Circulation Research, vol. 98, no. 8, pp. 1055-1063, 2006.

[220] R. Wiener, Y. Haitin, L. Shamgar et al., "The KCNQ1 (Kv7.1) $\mathrm{COOH}$ terminus, a multitiered scaffold for subunit assembly and protein interaction," The Journal of Biological Chemistry, vol. 283, no. 9, pp. 5815-5830, 2008.

[221] N. Zerangue, Y. N. Jan, and L. Y. Jan, "An artificial tetramerization domain restores efficient assembly of functional Shaker channels lacking T1," Proceedings of the National Academy of Sciences of the United States of America, vol. 97, no. 7, pp. 3591$3595,2000$.

[222] K. Asada, J. Kurokawa, and T. Furukawa, "Redox- and calmodulin-dependent S-nitrosylation of the KCNQ1 channel," The Journal of Biological Chemistry, vol. 284, no. 9, pp. 60146020, 2009.

[223] M. Furutani, M. C. Trudeau, N. Hagiwara et al., "Novel mechanism associated with an inherited cardiac arrhythmia: defective protein trafficking by the mutant HERG (G601S) potassium channel," Circulation, vol. 99, no. 17, pp. 2290-2294, 1999.

[224] C. T. January, Q. Gong, and Z. Zhou, "Long QT syndrome: cellular basis and arrhythmia mechanism in LQT2," Journal of Cardiovascular Electrophysiology, vol. 11, no. 12, pp. 1413-1418, 2000.

[225] H. M. Embark, C. Böhmer, V. Vallon, F. Luft, and F. Lang, "Regulation of KCNE1-dependent $\mathrm{K}+$ current by the serum and glucocorticoid-inducible kinase (SGK) isoforms," Pflügers Archiv, vol. 445, no. 5, pp. 601-606, 2003.

[226] N. Strutz-Seebohm, U. Henrion, K. Steinke, D. Tapken, F. Lang, and G. Seebohm, "Serum- and Glucocorticoid-inducible Kinases (SGK) regulate KCNQ1/KCNE potassium channels," Channels, vol. 3, no. 2, pp. 88-90, 2009.

[227] N. Nguyen, N. Kozer-Gorevich, B. L. Gliddon et al., "Independent trafficking of the KCNQ1 $\mathrm{K}+$ channel and $\mathrm{H}+-\mathrm{K}+-$ ATPase in gastric parietal cells from mice," American Journal of Physiology: Gastrointestinal and Liver Physiology, vol. 304, pp. G157-G166, 2013.

[228] I. S. Trowbridge, J. F. Collawn, and C. R. Hopkins, "Signaldependent membrane protein trafficking in the endocytic pathway," Annual Review of Cell Biology, vol. 9, pp. 129-161, 1993.
[229] S. Balla, V. Thapar, S. Verma et al., "Minimotif Miner: a tool for investigating protein function," Nature Methods, vol. 3, no. 3, pp. 175-177, 2006.

[230] M. D. Varnum, A. E. Busch, C. T. Bond, J. Maylie, and J. P. Adelman, "The min K channel underlies the cardiac potassium current $\mathrm{I}(\mathrm{Ks})$ and mediates species-specific responses to protein kinase C," Proceedings of the National Academy of Sciences of the United States of America, vol. 90, no. 24, pp. 11528-11532, 1993.

[231] Z. J. Zhang, N. K. Jurkiewicz, K. Folander, E. Lazarides, J. J. Salata, and R. Swanson, "K+ currents expressed from the guinea pig cardiac I(sK) protein are enhanced by activators of protein kinase C," Proceedings of the National Academy of Sciences of the United States of America, vol. 91, no. 5, pp. 1766-1770, 1994.

[232] T. Jespersen, M. Membrez, C. S. Nicolas et al., "The KCNQ1 potassium channel is down-regulated by ubiquitylating enzymes of the Nedd4/Nedd4-like family," Cardiovascular Research, vol. 74, no. 1, pp. 64-74, 2007.

[233] K. Krzystanek, H. B. Rasmussen, M. Grunnet et al., "Deubiquitylating enzyme USP2 counteracts Nedd4-2mediated downregulation of KCNQ1 potassium channels," Heart Rhythm, vol. 9, no. 3, pp. 440-448, 2012.

[234] T. Jespersen, H. B. Rasmussen, M. Grunnet et al., "Basolateral localisation of KCNQ1 potassium channels in MDCK cells: molecular identification of an N-terminal targeting motif," Journal of Cell Science, vol. 117, no. 19, pp. 4517-4526, 2004.

[235] J. P. David, M. N. Andersen, S. P. Olesen, H. B. Rasmussen, and N. Schmitt, "Trafficking of the IKs -complex in MDCK cells: site of subunit assembly and determinants of polarized localization," Traffic, vol. 14, pp. 399-411, 2013.

[236] M. Roura-Ferrer, L. Solé, A. Oliveras et al., "Impact of KCNE subunits on KCNQ1 (Kv7.1) channel membrane surface targeting," Journal of Cellular Physiology, vol. 225, no. 3, pp. 692-700, 2010.

[237] M. N. Andersen, K. Krzystanek, T. Jespersen, S.-P. Olesen, and H. B. Rasmussen, "AMP-activated protein kinase downregulates Kv7.1 cell surface expression," Traffic, vol. 13, no. 1, pp. 143-156, 2012.

[238] M. N. Andersen, S.-P. Olesen, and H. B. Rasmussen, "Kv7.1 surface expression is regulated by epithelial cell polarization," American Journal of Physiology: Cell Physiology, vol. 300, no. 4, pp. C814-C824, 2011. 

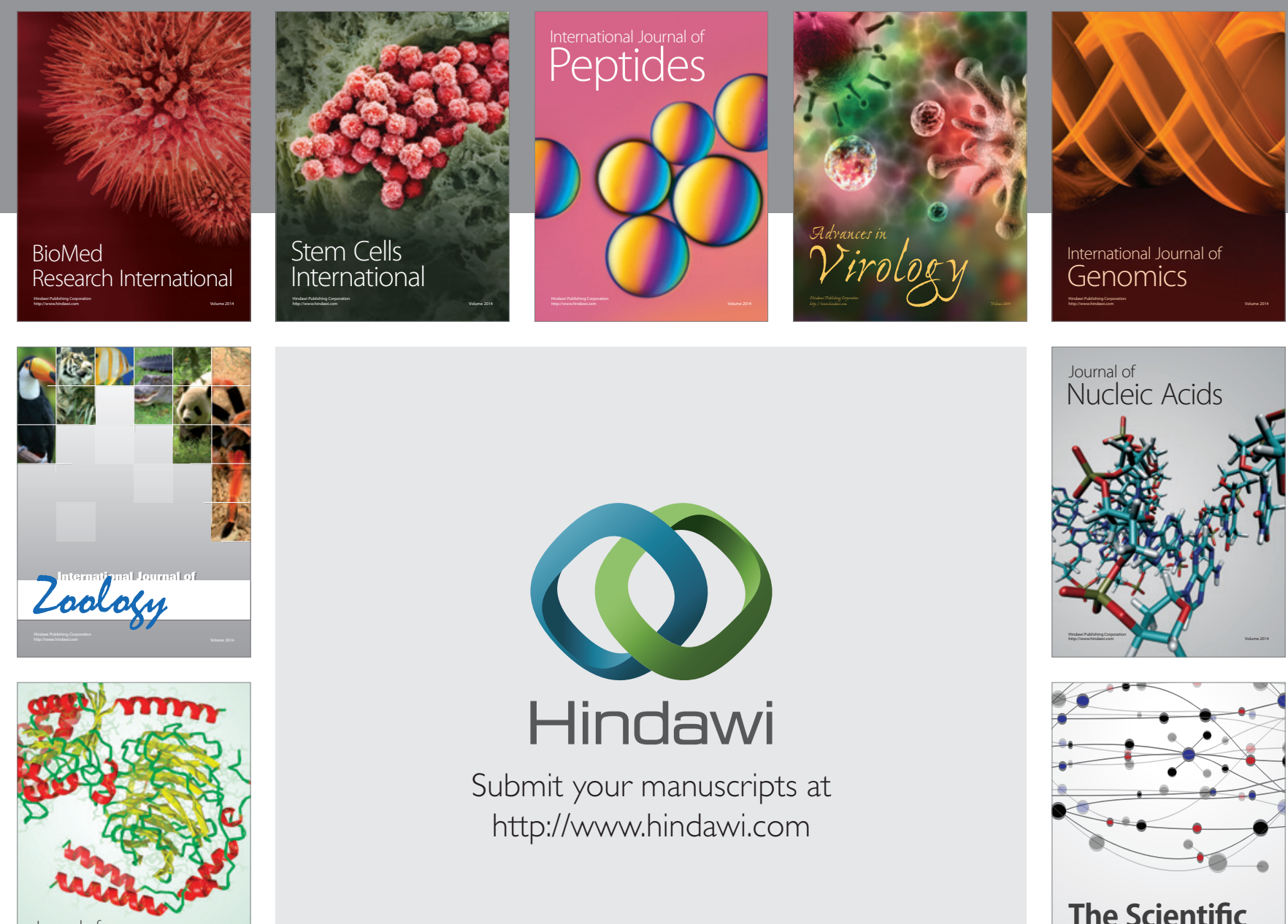

Submit your manuscripts at

http://www.hindawi.com

Journal of
Signal Transduction
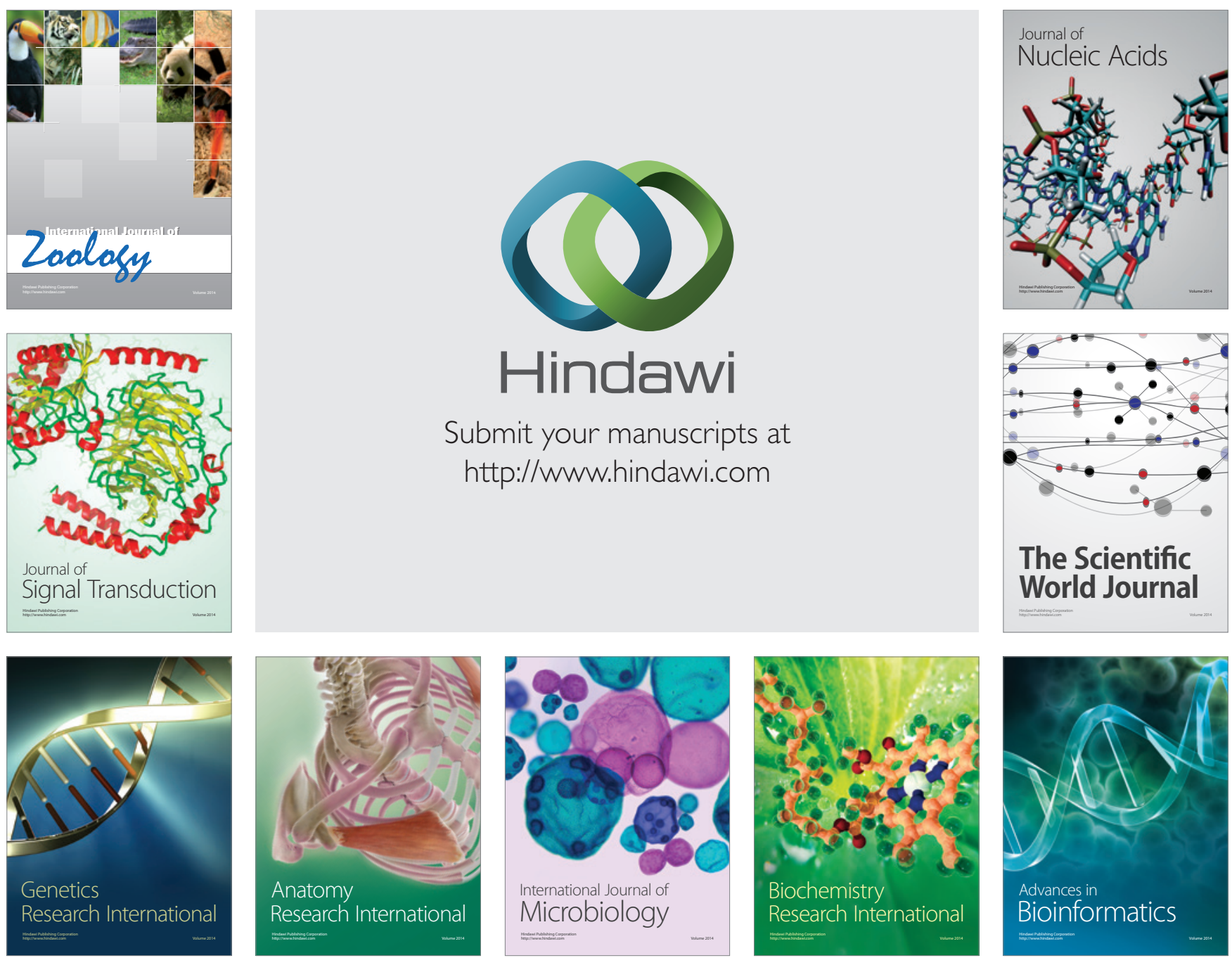

The Scientific World Journal
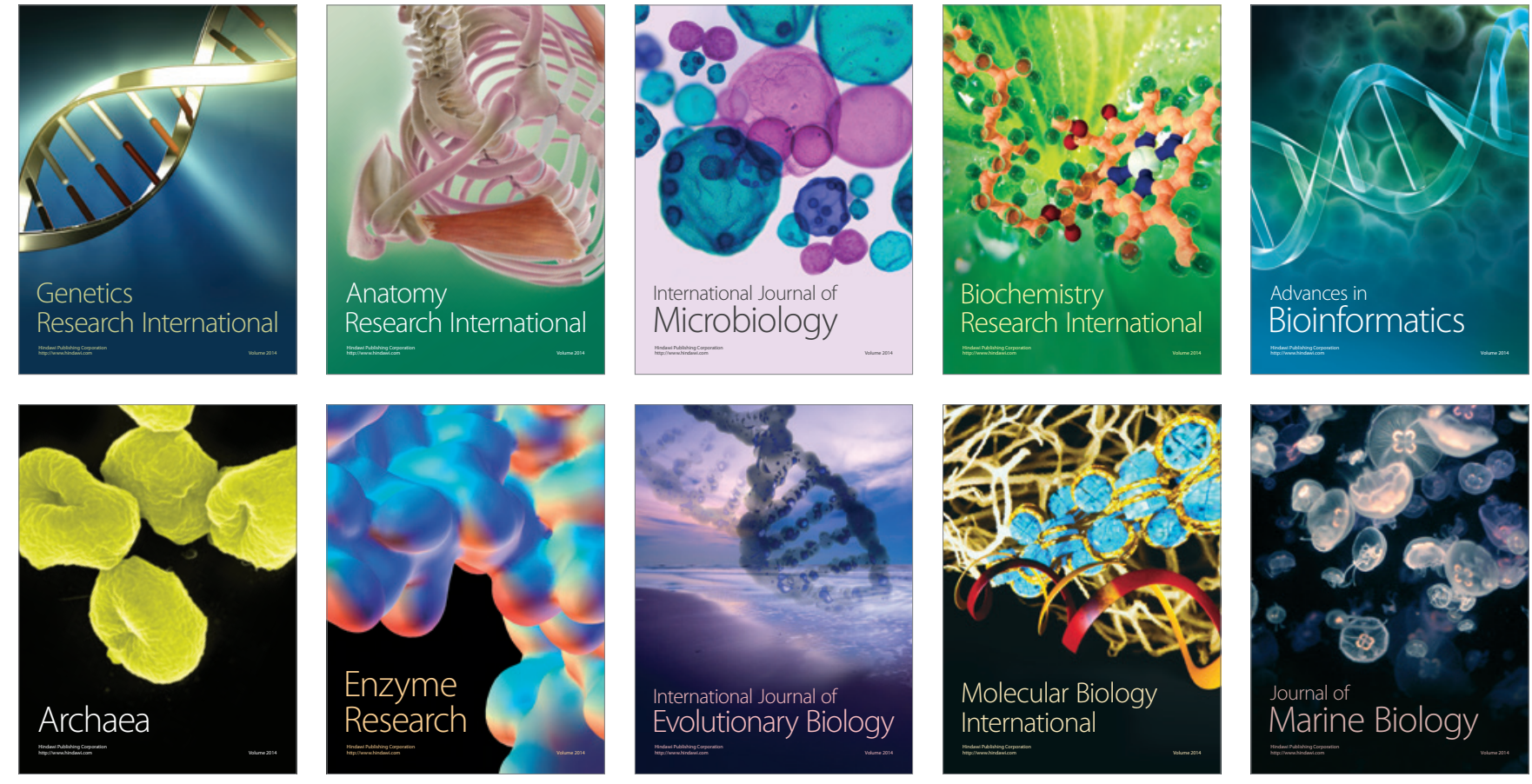